\title{
Comprendre les mécanismes de transmission sexuelle des virus : apports et limites des modèles in vitro
}

\author{
Julie Frouard \\ Anna Le Tortorec \\ Nathalie Dejucq-Rainsford \\ Université de Rennes, \\ Inserm, EHESP, \\ Institut de recherche en santé, \\ environnement et travail (Irset), \\ UMR_S 1085, \\ 9 av. du professeur Léon-Bernard \\ 35000 Rennes, France \\ $<$ nathalie.dejucq-rainsford@univ- \\ rennes1.fr>
}

\begin{abstract}
Résumé. Les virus sexuellement transmissibles, présents dans les sécrétions génitales, infectent les muqueuses génitales et colorectales du partenaire exposé via une large gamme de mécanismes, dictés par l'organisation de ces muqueuses et le virus lui-même. La compréhension des modes d'entrée dans l'organisme des virus transmis par voie sexuelle est nécessaire à l'élaboration de traitements permettant de bloquer ces infections. À ce titre, la modélisation in vitro de la transmission est indispensable. L'objectif de cette revue est de présenter les modèles et les méthodologies disponibles pour l'étude in vitro des interactions entre les muqueuses et les virus et pour l'évaluation préclinique de molécules antivirales, en explicitant leurs apports et leurs limites par rapport aux questions posées.
\end{abstract}

Mots clés : muqueuses génitales, virus sexuellement transmissibles, modèles in vitro

\begin{abstract}
Sexually transmitted viruses infect the genital and colorectal mucosa of the partner exposed to contaminated genital secretions through a wide range of mechanisms, dictated in part by the organization of the mucosa. Because understanding the modes of entry into the organism of viruses transmitted through sexual intercourse is a necessary prerequisite to the design of treatments to block those infections, in vitro modeling of the transmission is essential. The aim of this review is to present the models and methodologies available for in vitro study of interactions between viruses and mucosal tissue and for preclinical evaluation of antiviral compounds, and to point out their advantages and limitations according to the question being studied.
\end{abstract}

Key words: genital mucosa, sexually transmitted viruses, in vitro models

\section{Introduction}

L'objectif de cette revue est de présenter les méthodologies disponibles pour l'étude in vitro des modes d'entrée dans l'organisme humain de virus sexuellement transmissibles, en explicitant leurs apports et leurs limites par rapport aux questions posées. Le recours aux approches in vitro est indispensable à l'étude de la transmission sexuelle de pathogènes pour plusieurs raisons :

- ces approches permettent de se rapprocher de la physiologie et de la spécificité humaine, via l'utilisation de cellules primaires et de tissus humains. En effet, les modèles animaux, en particulier rongeurs, ne peuvent pas être direc-

Tirés à part : N. Dejucq-Rainsford tement extrapolés à l'homme et nécessitent des validations croisées ;

- l'analyse in vitro permet de disséquer de façon séquentielle les évènements conduisant à l'infection des muqueuses, des mécanismes de franchissement de la barrière épithéliale à l'infection des cellules cibles en passant par la reconnaissance des pathogènes par l'hôte et l'induction de la réponse immune locale ;

- la modélisation de la transmission au niveau muqueux est un outil indispensable à l'élaboration et au test de molécules visant à prévenir cette transmission ;

- l'utilisation de cellules et de tissus d'origine humaine s'inscrit dans une démarche éthique en réponse aux préoccupations sociétales sur l'expérimentation animale. Toutefois, pour une utilisation optimale de ces modèles, il importe de bien déterminer leurs avantages et leurs limites. 
Après une brève description des muqueuses susceptibles d'être exposées aux virus présents dans les sécrétions génitales et des différents mécanismes d'infection, nous présenterons un panorama des modèles d'étude in vitro disponibles, avant d'aborder plus en détail les études réalisées à ce jour et la pertinence de chaque modèle en fonction de la séquence d'évènement étudiée.

\section{Muqueuses exposées aux virus présents dans les sécrétions génitales}

D'une manière générale, les mécanismes de transmission virale sont dictés par l'organisation et la composition cellulaire de la muqueuse. Les muqueuses susceptibles d'être exposées à un virus sexuellement transmissible comportent des épithélia mono- ou pluristratifiés, plus ou moins kératinisés, qui reposent sur une lamina propria composée de fibroblastes, de cellules immunitaires, principalement lymphocytes $\mathrm{T}$, macrophages, cellules dendritiques, de vaisseaux sanguins bordés par l'endothélium et une couche plus profonde de cellules musculaires. Les cellules épithéliales muqueuses constituent une première barrière physique à l'environnement extérieur, plus ou moins efficace selon l'épaisseur de l'épithélium et l'organisation jonctionnelle entre les cellules. Elles représentent également une barrière chimique avec la sécrétion de cytokines/chimiokines et de molécules à activité antimicrobienne (e.g. alpha- et bêta-défensines, lactoferrine, lysozyme), et jouent ainsi un rôle critique dans la défense de l'organisme face aux pathogènes [1]. Ces cellules ont le double rôle de répondre directement aux pathogènes et de signaler l'agression en cours aux cellules du système immunitaire inné et acquis. Pour cela, les cellules épithéliales muqueuses expriment, selon leur origine tissulaire, un répertoire de récepteurs de reconnaissance de motifs moléculaires (PRR) qui permet la reconnaissance de différents stimuli antigéniques auxquels elles seront exposées. D'une manière générale, la reconnaissance d'un antigène viral ou bactérien par les PRR conduit à la sécrétion d'un panel de cytokines pro-inflammatoires (IL-6, IL-8, TNF $\alpha$, SDF- $1 \ldots$. ), de $\beta$-chimiokines (MIP- $1 \alpha$ et $-1 \beta \ldots$. ), mais également d'interféron $\beta$ qui joue un rôle majeur dans la mise en place de l'immunité antivirale [1].

\section{Muqueuses génitales féminines}

Le vagin et le col de l'utérus représentent les principales portes d'entrée dans l'organisme de la femme pour un virus transmis par le sperme. L'endomètre et les trompes de Fallope représentent d'autres sites d'entrée potentiels, mais leur exposition aux pathogènes présents dans le sperme n'est pas clairement établie. Les muqueuses du vagin et de la partie basse du col de l'utérus, l'exocol, sont recouvertes d'un épithélium pavimenteux pluristratifié dont l'épaisseur - 15 à 30 couches de cellules - varie pour le vagin au cours du cycle menstruel. On trouve, enchâssés dans ces épithélia, des lymphocytes T mémoires, préférentiellement CD8+, et des cellules de Langerhans connues pour jouer un rôle important dans la transmission virale, notamment du virus de l'immunodéficience humaine (VIH), à travers la muqueuse génitale [2]. Des lymphocytes T mémoires résidents mais également recirculants (CD4+, CCR7+, CD69-) qui trafiquent entre les tissus périphériques et le tissu lymphoïde, et des macrophages de phénotype monocytaire sont également présents dans la lamina propria de ces épithélia, tandis que les lymphocytes B et les cellules NK sont plus rares à ce niveau [3-5]. On note également la présence dans la lamina propria de cellules dendritiques majoritairement myéloïdes, avec un phénotype muqueux CD11b+, CD14+ qui les différencie des cellules dendritiques conventionnelles [6-8]. Ces cellules dendritiques expriment également une lectine de type $\mathrm{C}$ particulière, DC-SIGN, qui joue un rôle fondamental dans la capture et la transmission de plusieurs agents infectieux notamment du VIH et du cytomégalovirus (CMV) [3]. D’une manière générale, les muqueuses du vagin et de l'exocol présentent une concentration en cellules immunes nettement plus faible que les muqueuses de l'endocol et de l'utérus.

Les muqueuses de l'utérus et de la partie haute du col de l'utérus, l'endocol, sont recouvertes d'un épithélium prismatique monostratifié sous lequel on observe de nombreux agrégats lymphoïdes composés de lymphocytes B entourés par des lymphocytes T CD8+ et un halo de macrophages. On note également, entre ces agrégats, la présence éparse de lymphocytes T CD4+ préférentiellement Th17, de cellules dendritiques et de nombreuses cellules NK $[1,7,9]$. Contrairement aux autres niveaux du tractus génital féminin, les cellules dendritiques de la muqueuse utérine sont CD103+. La fonction particulière de ces cellules dendritiques CD103+ reste à définir, mais une étude en modèle murin indique qu'elles pourraient jouer un rôle critique dans l'induction spécifique de la prolifération des lymphocytes $\mathrm{T}$ régulateurs nécessaires au maintien de la tolérance immunitaire à ce niveau $[7,10]$ et pourraient ainsi expliquer l'absence relative de LT TH17 dans la muqueuse utérine par rapport aux autres organes du tractus génital féminin [9]. Les cellules épithéliales endométriales expriment un très large panel de PRR (TLR1-9, NOD1 et NOD2) indiquant un large potentiel de réponse aux pathogènes [1]. Les TLR1-3 et 6 sont exprimés au niveau de l'épithélium de l'endocol [1].

Entre l'exocol et l'endocol, on distingue la zone de transition qui, histologiquement, se traduit par un changement 
abrupt de la surface épithéliale qui passe d'un épithélium pluristratifié à un épithélium monostratifié. La muqueuse de la zone de transition est celle du tractus génital féminin qui contient le plus de cellules immunitaires. De ce fait, cette zone est considérée comme la plus sensible à l'infection par le VIH et les papillomavirus (HPV) [11].

Les cellules épithéliales de l'endocol et de l'endomètre sécrètent un épais mucus qui recouvre également la muqueuse vaginale. Au-delà de sa fonction primaire pour la fécondation, ce mucus participe à la prévention de l'entrée des pathogènes en les emprisonnant.

\section{Muqueuses génitales masculines}

Chez l'homme, les tissus du tractus génital exposés aux infections sexuellement transmissibles sont le prépuce, qui couvre le gland du pénis, et l'urètre. Le prépuce est recouvert d'un épithélium pluristratifié kératinisé dont le degré de kératinisation est moins important sur sa face interne en contact avec le gland [12]. On retrouve, enchâssés dans cet épithélium pluristratifié, des cellules de Langerhans et de nombreux lymphocytes T CD8+ mémoires. Les cellules immunitaires dans la lamina propria sont majoritairement des macrophages et lymphocytes $\mathrm{T}$ mémoires, essentiellement CD8+ [13]. L'urètre du pénis est décrit comme une voie d'entrée majeure pour la plupart des infections sexuellement transmissibles chez l'homme [14, 15]. Cette muqueuse, recouverte d'un épithélium pseudostratifié cylindrique non kératinisé, évolue vers un épithélium pluristratifié non kératinisé puis kératinisé au niveau de l'ouverture distale de l'urètre. La muqueuse épithéliale de l'urètre est l'une des rares muqueuses génitales à exprimer le TLR9. Ce récepteur permet la reconnaissance d'acides nucléiques viraux et joue un rôle important dans la défense immunitaire antivirale [13]. On retrouve des cellules immunitaires aux différents niveaux de l'urètre : macrophages, lymphocytes T CD8+ mémoires et cellules de Langerhans enchâssés dans l'épithélium pluristratifié ; cellules NK, lymphocytes TCD4+et CD8+ mémoires ainsi qu'une petite population de lymphocytes $\mathrm{T}$ naïs dans la lamina propria de l'épithélium pseudostratifié [1]. La majorité des lymphocytes $\mathrm{T}$ dans la lamina propria ou infiltrant l'épithélium de l'urètre ont un phénotype mémoire et ils expriment CD103, l'intégrine $\alpha E \beta 7$, une molécule d'adhésion qui permet l'adhésion des lymphocytes sur les cellules épithéliales [14]. Les cellules dendritiques ne sont pas retrouvées dans la muqueuse de l'urètre.

\section{Muqueuses anales et colorectales}

La muqueuse anale est formée d'un épithélium pluristratifié kératinisé histologiquement proche des muqueuses vaginales et de l'ectocol. La muqueuse colorectale, située juste en amont de la muqueuse anale, est formée d'un épithélium cylindrique monostratifié. Les cellules épithéliales du côlon expriment un large panel de récepteurs de reconnaissance de motifs pathogènes, les TLR1-9 [16]. À la surface basolatérale de cet épithélium, de nombreuses cellules immunitaires sont présentes : lymphocytes $\mathrm{T}$, lymphocytes $\mathrm{B}$, cellules $\mathrm{NK}$, cellules dendritiques, cellules de Langerhans et de nombreux macrophages CD14+, CD68+, CD163+ et DCSIGN+ de phénotype M2 (anti-inflammatoire), ce qui fait de cette muqueuse un site privilégié pour l'entrée de virus ciblant les cellules immunitaires tels que le VIH $[17,18]$. Entre les muqueuses anales et du côlon, la zone de transition ou jonction anorectale présente un épithélium pluristratifié non kératinisé.

\section{Modes d'infection des muqueuses exposées aux sécrétions génitales (figure 1)}

Certains virus sexuellement transmissibles, tels que les virus de la famille Herpes simplex (HSV) ou les HPV, sont capables d'infecter de façon productive les cellules épithéliales recouvrant les muqueuses. Les virus qui n'infectent pas de façon productive les cellules épithéliales (e.g. VIH ou les virus T-lymphotrophiques humains HTLV-1 et -2) vont nécessiter pour propager l'infection à leurs cellules cibles sous-épithéliales soit une perte de l'intégrité de la barrière épithéliale, soit la mise en place d'un mécanisme d'infection qui permettra d'outrepasser cette barrière. Ainsi, le virus pourra atteindre les cellules cibles sous-épithéliales par :

- simple diffusion au travers de brèches résultant de microabrasions de la barrière épithéliale lors d'actes sexuels ou de la présence d'une inflammation liée à une infection préalable de la muqueuse ;

- capture des particules virales par les extensions de cellules dendritiques sub-muqueuses, ces dernières participant ensuite à la dissémination du virus en sous-muqueux mais aussi au niveau systémique ;

- passage actif de cellules infectées entre les cellules épithéliales par transmigration, sans altération de l'intégrité de la barrière épithéliale ;

- transcytose à travers la barrière épithéliale de particules virales libres ou provenant de cellules infectées, ce qui correspond au transport polarisé et vésiculaire de particules virales à l'intérieur des cellules épithéliales du pôle apical vers le pôle basal sans infection productive de la cellule traversée $[19,20]$.

D'une manière générale, malgré l'expression de jonctions serrées entre les cellules épithéliales, les épithélia monostratifiés, moins épais, sont plus fragiles que les épithélia pluristratifiés et plus susceptibles à la formation de brèches. À l'inverse, des jonctions plus lâches sont observées dans les épithélia pluristratifiés, ce qui favorise l'infiltration de ces épithélia par les cellules immunitaires, cibles 


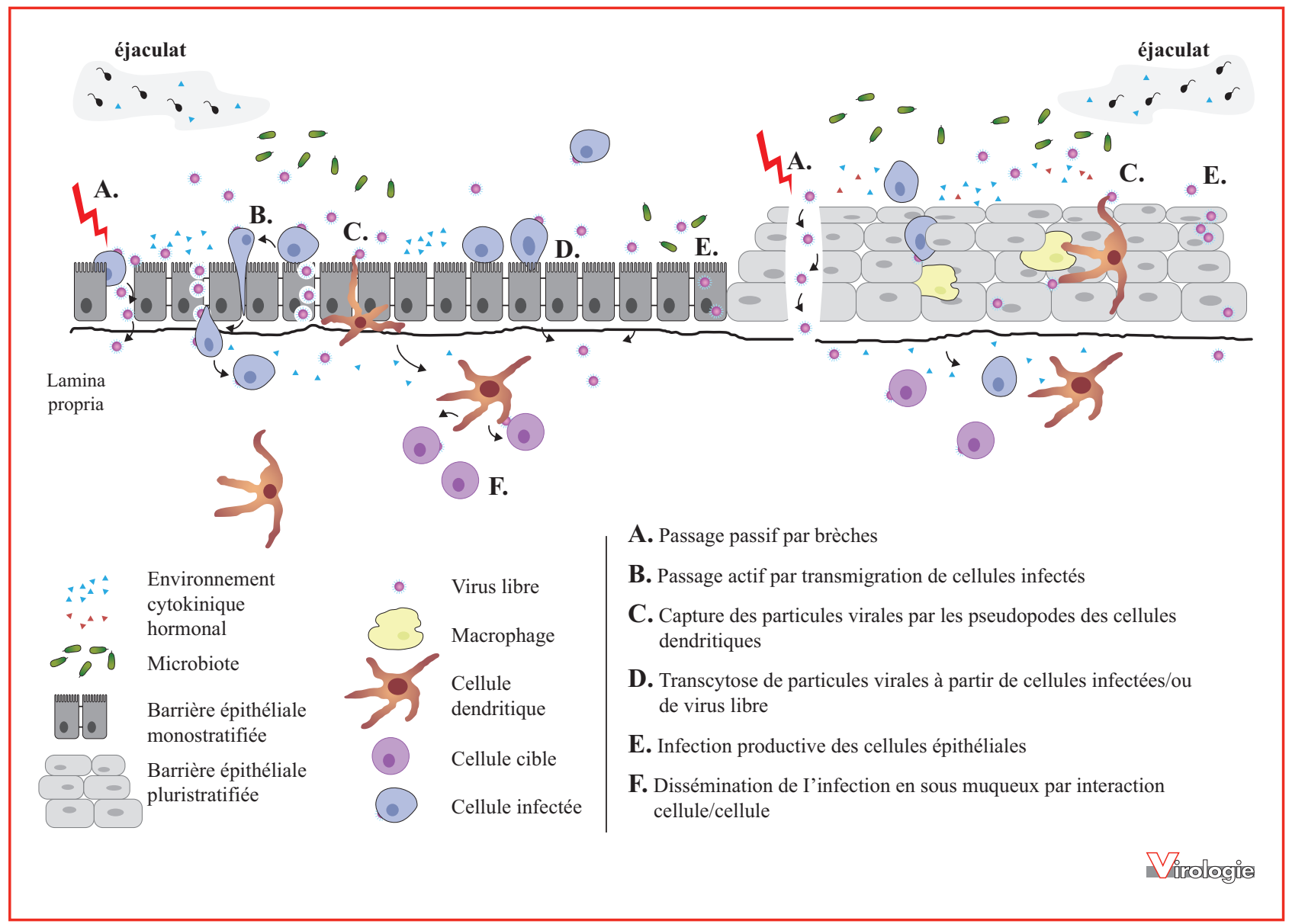

Figure 1. Représentation schématique des mécanismes d'entrée des virus sexuellement transmissibles à travers les muqueuses.

potentielles de virus tels que le $\mathrm{VIH}$, et contribue à la propagation de l'infection virale.

L'imprégnation hormonale des muqueuses, leur microbiote ainsi que leur exposition aux fluides génitaux lors de rapport sexuel sont des facteurs qui vont pouvoir influencer l'infection des muqueuses [21]. Par exemple, l'exposition des muqueuses du tractus génital féminin au liquide séminal stimule la production de cytokines proinflammatoires par les cellules épithéliales in vitro et in vivo, et en conséquence favorise l'activation et le recrutement de cellules immunitaires telles que les lymphocytes, cibles pour des pathogènes tels que le VIH $[22,23]$. In vitro, l'exposition des muqueuses aux fluides génitaux peut moduler l'expression des molécules d'adhésion exprimées par les cellules épithéliales, telles que les molécules de jonctions serrées ZO-1 et les claudines [24, 25]. Par ailleurs, l'opsonisation des virions par les protéines du complément présentes dans les fluides génitaux (sperme et sécrétions vaginales) pourrait moduler l'infectiosité des cellules mucosales (cellules dendritiques, lymphocytes CD4+ et cellules épithéliales) avec un effet différentiel selon le type cellulaire [26-28]. Il a été décrit dans le sperme plusieurs peptides cationiques (e.g. un dérivé de la phosphatase alcaline prostatique dénommé semen-derived enhancer of virus infection [SEVI]), ainsi que plusieurs fragments de la séménogéline) capables d'augmenter l'infectiosité des virus VIH et CMV in vitro en favorisant l'attachement de ces virus aux cellules par le jeu d'interactions électrostatiques [29, 30]. Cet effet, qui n'a à ce jour pas été démontré in vivo, est cependant contrecarré, dans le cas du VIH, par la présence dans le sperme des hommes infectés de la chimiokine CCL5, qui inhibe l'entrée du virus dans les lymphocytes T CD4+ [31]. De plus, d'autres molécules du sperme, la clusterine et la mucine 6 , inhibent la fixation du VIH médiée par DC-SIGN aux cellules dendritiques $[32,33]$. Ainsi, les sécrétions génitales, via leurs effets sur les pathogènes, les cellules épithéliales et les cellules immunitaires des muqueuses, peuvent influer sur l'infection. 


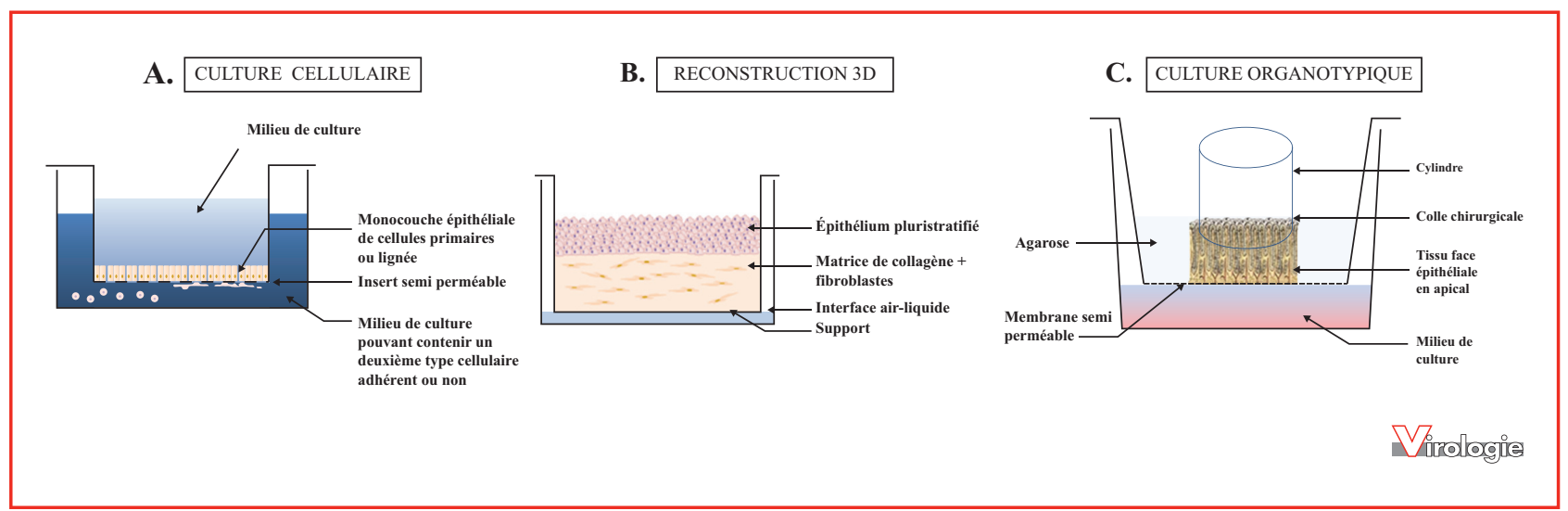

Figure 2. Représentation schématique des différents systèmes de cultures in vitro des muqueuses mono- et pluristratifiées.

\section{Panorama des différents types de modèles d'étude in vitro}

Nous présentons ci-dessous une description générale des différents modèles qui ont été développés pour l'étude des mécanismes d'infection des muqueuses par les virus sexuellement transmissibles in vitro (figure 2).

\section{Cultures de cellules épithéliales immortalisées}

Les lignées cellulaires utilisées pour l'étude de l'infection des muqueuses sont soit des cellules épithéliales isolées d'un adénocarcinome (e.g. cellules cervicales HeLa), soit des cellules immortalisées par transduction avec un vecteur rétroviral, telles que les lignées endométriales HEC-1, endocervicales End1/E6E7, colorectales Caco2 ou encore d'épithélium buccal TR 146. L'avantage des lignées est qu'elles sont bien caractérisées et standardisées et, contrairement à tous les modèles primaires, représentent un matériel biologique facilement accessible. De plus, l'extinction de l'expression de gènes cellulaires par siRNA ou au contraire la surexpression génique peuvent être plus facilement expérimentées dans ces modèles de lignées cellulaires, ce qui permet d'appréhender aisément les mécanismes moléculaires de l'infection et/ou de la réponse antivirale. À titre d'exemple, l'activité antivirale des peptides cationiques antimicrobiens Trappin-2 et Elafin a pu être mise en évidence par extinction ou surexpression de ces gènes cellulaires dans un modèle de lignée de cellules endométriales HEC-1 ou endocervicale End1/E6E7 infectées par le HSV-2 [34]. Toutefois, aujourd'hui, la manipulation génique dans les systèmes de culture primaire est nettement facilitée par la nouvelle technologie d'édition de gènes CRIsP/Cas9.

La culture de certaines lignées épithéliales permet également d'aboutir à la formation d'une monocouche de cellules épithéliales pleinement différenciées et polarisées, avec un pôle basal et un pôle apical, et l'expression de jonc- tions serrées entre les cellules épithéliales, caractéristiques des monocouches épithéliales bordant les muqueuses. Pour cela, les cellules sont généralement cultivées huit à dix jours à confluence sur des inserts semi-perméables recouverts ou non d'un support protéique type matrigel. Lorsque les cellules sont confluentes, elles vont commencer à se différencier et se polariser. La polarisation de la culture de cellules épithéliales se vérifie par mesure de la résistance transépithéliale avec un ohmmètre, visualisation de l'expression de jonctions serrées ou encore en testant le passage extracellulaire de molécules à haut poids moléculaire (e.g. dextran). La polarisation relativement aisée de certaines lignées épithéliales en fait un moyen facile pour appréhender les mécanismes de passage de particules virales ou cellules infectées à travers la barrière épithéliale ( $c f$. section « Choix des modèles par rapport aux questions posées »).

\section{Cultures primaires de cellules épithéliales}

L'utilisation de cellules primaires, isolées à partir de tissus frais, permet de s'affranchir des artéfacts potentiels liés à l'utilisation de cultures immortalisées, lesquelles présentent des caractéristiques modifiées par rapport aux cellules primaires pouvant influer sur l'infection virale. D'une manière générale, l'isolement des cellules épithéliales se fait par digestion enzymatique du tissu, le plus souvent avec de la pancréatine, de la hyaluronidase et/ou de la collagénase, associée ou non à une digestion mécanique [35]. Certaines cellules épithéliales isolées peuvent être cultivées en monocouche polarisée de la même façon que les lignées. Une fois la monocouche formée, les cellules restent viables en culture environ deux semaines. Toutefois, cette polarisation peut être plus difficile à obtenir [36]. En effet, la purification des cellules primaires peut compromettre la fonction de la barrière épithéliale et empêcher la reformation de jonctions serrées nécessaires à la polarisation. 


\section{Co-cultures cellules épithéliales/cellules des sécrétions génitales ou de la lamina propria}

Les systèmes de co-culture consistent à cultiver simultanément différents types cellulaires primaires ou de lignées issues d'un même tissu susceptibles d'interagir dans la transmission du virus. Classiquement, dans un système de culture à deux chambres, on ajoute à une culture confluente de cellules épithéliales primaires ou d'une lignée épithéliale (polarisée ou non) sur insert, un autre type cellulaire. Ainsi, des systèmes de co-culture cellules épithéliales/lymphocytes ou monocytes/macrophages (primaire ou lignée) ajoutés dans l'insert, c'est-à-dire sur le pôle apical des cellules épithéliales, ont été développés pour mimer les contacts entre les cellules épithéliales et les cellules présentes dans les sécrétions du donneur [24]. Il existe également des systèmes où les deux types cellulaires co-cultivés sont adhérents. C'est notamment le cas des cocultures de cellules épithéliales et de cellules dendritiques [37]. Dans ce dernier cas, après polarisation des cellules épithéliales sur insert, la chambre de culture est retournée et les cellules dendritiques déposées sur la face opposée de l'insert. Après quelques heures, lorsque les cellules dendritiques ont adhéré à l'insert, le système est remis en place, la face basale des cellules épithéliales reposant sur l'insert et les cellules dendritiques adhérant sous l'insert et donc sous la face basale des cellules épithéliales. Les systèmes de co-culture permettent d'analyser les interactions entre la barrière épithéliale et les différents types cellulaires présents dans les sécrétions génitales ou en sous-muqueux lors d'une transmission virale. Toutefois, il faut noter que les systèmes utilisés à ce jour restent assez peu physiologiques : les cellules épithéliales mises en culture sont souvent issues de lignées immortalisées ou bien les cellules représentant les cellules des sécrétions génitales ou de la lamina propria proviennent de leucocytes immortalisés ou isolés du sang.

\section{Reconstructions 3D de muqueuses pluristratifiées}

Depuis quelques années, un nouveau type de modèle voit le jour, les reconstructions 3D de muqueuses génitales. Ces modèles permettent de reconstituer in vitro les épithélia pluristratifiés caractéristiques des muqueuses vaginales, de l'exocol, du prépuce ou de l'urètre, ce qui jusqu'ici était impossible avec les cultures simples de lignées ou primaires, lesquelles ne permettent pas la pluristratification des cellules. D'une manière générale, il s'agit de cultiver les cellules épithéliales primaires ou immortalisées quelques jours sur une matrice de collagène et de cellules nourricières de type fibroblaste. Ce support a pour but de mimer la lamina propria muqueuse. L'ensemble matrice/cellules épithéliales est ensuite placé à l'interface air-liquide ou bien submergé dans le milieu de culture. Les cellules épithéliales se stratifient et se différencient alors en un épithélium mimant celui du tissu d'origine [38]. Il existe des modèles améliorés intégrant des cellules immunes classiquement retrouvées enchâssées entre les cellules épithéliales. Dans ces modèles, les cellules immunitaires de type cellules dendritiques, cellules de Langerhans ou macrophages sont ajoutées au moment de la co-culture matrice/cellules épithéliales [12, 15, 39, 40]. La mise en place de ces modèles est relativement longue puisqu'il faut compter cinq à huit semaines pour obtenir une reconstruction complète avec un épithélium pluristratifié et polarisé. À l'avantage des cultures organotypiques, ces systèmes de reconstruction 3D constituent des modèles de barrières épithéliales homogènes où l'architecture tissulaire peut être maintenue intacte un temps suffisant à l'étude de leur infection. Toutefois, ils n'ont pas la valeur physiologique des cultures organotypiques, puisqu'ils sont constitués d'un mélange de populations cellulaires primaires et immortalisées, souvent issues de différents tissus ou dérivés du sang.

\section{Cultures organotypiques}

Les cultures organotypiques constituent $a$ priori le modèle le plus intégratif et physiologique dont les chercheurs disposent aujourd'hui pour l'étude in vitro des mécanismes de transmission des virus sexuellement transmissibles. Il existe des modèles de cultures organotypiques des différents organes des tractus génitaux masculins et féminins, tels que la culture d'explants de prépuce, d'exocol, d'endocol, de vagin ou bien encore de tissu colorectal. Il s'agit de mettre en culture des fragments de tissu sain comprenant l'épithélium et la sous-muqueuse, obtenus après chirurgie et coupés en petits blocs de quelques millimètres cubes pour éviter l'anoxie au centre du tissu. La culture du tissu se fait le plus souvent à l'interface airliquide ou quelquefois de façon submergée dans le milieu de culture. Dans le premier cas, les fragments de tissu sont disposés sur des membranes poreuses de polycarbonate ou de collagène dans des systèmes à deux chambres ou encore sur des éponges de gélatine (gelfoam). Dans ces systèmes, il est possible de polariser la transmission virale, c'est-àdire restreindre l'application de virus à la face apicale de l'épithélium afin de mimer au mieux les mécanismes de la dissémination virale. Pour cela, le tissu est orienté, lors de sa mise en culture, face épithéliale vers le haut et face sous-muqueuse en contact avec la membrane ou le gelfoam. Deux stratégies majeures sont utilisées :

- la première consistant à entourer l'explant d'agarose afin de ne laisser accessible que la face épithéliale aux différents composés [41-44] ;

- la seconde étant de fixer un cylindre avec de la colle chirurgicale sur la face épithéliale du tissu, permettant là encore une application des substances directement dans 
le cylindre et donc de façon restreinte à la face apicale $[4,12,15,37,45,46]$.

L'association de ces deux stratégies permet d'assurer au mieux la polarisation de la culture.

L'avantage majeur des cultures organotypiques est qu'elles permettent de conserver en culture l'architecture tissulaire originale. L'infection polarisée de ces fragments de tissu permet donc de mimer le plus physiologiquement possible les mécanismes de transmission virale au niveau des muqueuses. Cependant, il faut noter que le maintien de cette architecture peut être très court selon les tissus étudiés. Une limite importante est en effet la durée de survie limitée de certains types cellulaires dans le tissu, qui sont moins bien « nourris » qu'en système de culture 2D, soit en raison d'un accès plus restreint aux nutriments, soit parce que le milieu de culture utilisé doit représenter un compromis par rapport aux besoins des différents types cellulaires. Le maintien de l'intégrité des barrières épithéliales des explants est ainsi très variable selon l'origine tissulaire et l'enrichissement du milieu de culture. D'une manière générale, les strates les plus superficielles des épithélia pluristratifiés sont perdues dès 24 à 48 heures de culture $[42,43]$. De plus, les cellules immunes enchâssées dans ces épithélia émigrent hors du tissu dès les premières heures de culture. En ce qui concerne les muqueuses à épithélium monostratifié, il existe une grande hétérogénéité selon l'origine du tissu : les épithélia de l'endocol sont maintenus en culture de façon intègre quatre à six jours [42], alors que les épithélia du côlon sont beaucoup plus fragiles, l'intégrité de l'épithélium en culture n'excédant pas six heures de culture en conditions classiques (incubateurs conventionnels) [37, 41, 47] et 24 heures en atmosphère enrichie en oxygène [48]. Dans tous les cas, l'intégrité du tissu est conditionnée par une mise en culture extrêmement rapide après l'excision chirurgicale. La viabilité des tissus est évaluée le plus souvent par simple analyse morphologique et par un test de viabilité au bromure de 3-(4,5-dimethylthiazol-2-yl)-2,5-diphenyl tetrazolium (MTT). Enfin, une limite importante à l'utilisation de tous les modèles primaires est l'approvisionnement en tissu humain, qui peut être rare ou irrégulier selon les organes, et nécessite l'établissement d'une déclaration de collection de matériel biologique auprès du ministère de la Santé et l'examen de la demande par un comité d'éthique.

\section{Choix des modèles par rapport aux questions posées}

Au travers d'exemples illustrant les résultats obtenus grâce aux différents modèles, nous chercherons, dans cette partie, à mettre en exergue les avantages et les limites de chacun de ces modèles pour étudier les différentes étapes de la transmission muqueuse de pathogènes.

\section{Étude de la provenance des virus dans les sécrétions génitales}

La contamination des sécrétions génitales par des particules virales et/ou des cellules infectées est à l'origine de la transmission au niveau des muqueuses du partenaire sexuel. Une question sous-étudiée est celle de la provenance des virus dans les sécrétions génitales. Cette question est particulièrement prégnante en ce qui concerne le sperme, lequel représente un vecteur important pour de nombreux virus. Or, s'il a longtemps été considéré que les virus systémiques présents au niveau du sperme provenaient d'une diffusion passive de particules virales et de cellules infectées issues de la circulation sanguine, il est maintenant établi que ce n'est pas la seule source. Pour preuve, des analyses phylogénétiques chez des hommes infectés par le VIH-1 ont montré que, pour environ $60 \%$ d'entre eux, les populations virales du sperme sont distinctes de celles du sang [49]. Un autre élément est la persistance de virus dans le sperme en dépit d'une virémie négative ou indétectable. C'est le cas notamment du VIH-1, qui persiste dans le sperme de certains patients sous traitement antirétroviral efficace, ainsi que des virus Ebola et Zika, qui peuvent perdurer plusieurs mois dans le sperme d'hommes guéris. Ces éléments indiquent l'existence de sources locales, qu'il est crucial d'élucider pour déterminer l'origine de ces virus dans le sperme. Pour tester la permissivité aux virus des organes qui produisent le sperme, les modèles ex vivo de tissus humains sont très utiles car il est impossible d'étudier les organes du tractus génital des hommes infectés. Nous avons ainsi démontré l'infection ex vivo par le VIH-1 d'explants humains de testicule, de prostate et de vésicule séminale dans des modèles de culture organotypique, et mis en évidence la nature des cellules infectées [50-52]. Il est néanmoins important de valider les résultats obtenus ex vivo par des approches in vivo chez l'animal, en particulier en modèle primate non humain, ce dernier procurant en outre l'avantage de pouvoir étudier en parallèle l'infection des sources locales et du sperme [53].

\section{Étude des mécanismes d'infection de la barrière épithéliale}

La culture primaire polarisée de cellules épithéliales représente un modèle intéressant pour l'étude de l'infection des épithélia monostratifiés. MacDonald et al. et Nazli et al. ont ainsi développé des cultures primaires polarisées de cellules épithéliales endométriales et endocervicales pour étudier l'infection de ces tissus par HSV-2, un virus ayant un tropisme pour les épithélia génitaux monostratifiés 
de l'endocol et de l'endomètre [54, 55]. La monocouche polarisée, reconstituée après digestion des tissus est exposée au virus, et la permissivité des cellules à l'infection sont évaluées par mesure du relargage de virus dans le surnageant basal et par mise en évidence des cellules infectées par microscopie confocale. Ce modèle simplifié leur a permis d'étudier l'effet direct de différents stimuli sur l'infection des cellules épithéliales, telles que les variations d'hormones sexuelles (progestérone) ou de molécules à activité antivirale [54]. Ils ont ainsi démontré que le Poly IC, un ARN double brin synthétique, ligand de TLR3, induit une protection significative des cellules épithéliales génitales à l'infection HSV-2, laquelle est corrélée à la production d'IFN $\beta$ et d'acide nitrique par les cellules épithéliales. Cela met en jeu les voies de signalisation NFкB et IRF3 [55].

Toutefois, dans le cas du VIH-1, l'utilisation de cellules épithéliales génitales issues de lignées ou en culture primaire a généré des résultats divergents. Ainsi, Howell et al. ont initialement décrit les cellules épithéliales primaires du col de l'utérus, de l'utérus et des trompes de Fallope comme permissives à l'infection par le VIH-1 (détection intracellulaire de la protéine virale neuf à cinq jours post-infection et test d'infectiosité positif), tandis que Greenhead et al. n'ont détecté ni infection (absence de détection d'ADN viral par PCR), ni passage de virus (absence de détection de la p24 dans les surnageants et test d'infectiosité négatif) à dix jours post-infection dans des cultures primaires de cellules épithéliales d'exocol et d'endocol infectées par du virus libre ou après co-culture avec des cellules infectées [56, 57]. Des résultats contradictoires ont également été obtenus dans des lignées de cellules épithéliales : à titre d'exemple, Micsenyi et al. ont montré une infection productive des lignées épithéliales d'exocol (Ect1 E6/E7) et d'endocol (End1 E6/E7) en démontrant que l'infection des cellules peut être inhibée par des inhibiteurs de la reverse transcriptase et de l'intégrase [58]. À l'inverse, d'autres études ont démontré que ces deux lignées et d'autres lignées épithéliales originaires des mêmes tissus (e.g. lignée ME180 dérivée de cellules épithéliales cervicales) ne sont pas productivement infectées par le VIH-1 [59, 60]. Sur la base d'études in vivo dans des modèles simiens, le consensus actuel est que les cellules épithéliales des muqueuses vaginales et rectales ne sont pas infectées de façon productive par le VIH-1 [61-64].

Les résultats discordants obtenus sur la productivité de l'infection pour une même lignée ou culture primaire peuvent être liés à des variations de plusieurs paramètres, tels que le protocole d'infection (souche virale, quantité de virus inoculé ou temps d'exposition), le protocole d'isolement des cellules primaires (perte plus ou moins importante des récepteurs/corécepteurs du VIH-1 lors de la dissociation du tissu) et le degré de polarisation de ces cellules. Plus largement et comme indiqué ci-dessus, il faut garder à l'esprit que les cellules immortalisées, bien qu'étant originaires des tissus d'intérêt, ne conservent pas toutes les caractéristiques morphologiques et biochimiques des cellules primaires du tissu d'origine. La composition en lipides, protéines et la glycosylation des lignées transformées diffèrent grandement des cellules primaires [36]. Ces différences peuvent donc influencer, voire modifier, le mécanisme d'entrée virale et d'infection des cellules par comparaison avec la situation in vivo. Ainsi, bien qu'indispensable à l'étude des mécanismes d'infection et de passage des différents virus, les modèles simplifiés de culture isolée de cellules épithéliales primaires ou de lignée nécessitent des validations dans des modèles plus intégrés. La mise au point depuis quelques années des modèles de reconstruction $3 \mathrm{D}$ a permis notamment de mieux comprendre les phases précoces des infections HSV dans les épithélia génitaux pluristratifiés [65, 66]. En effet, dans un épithélium pluristratifié, les cellules épithéliales ont un programme d'expression génique différent en fonction de leur position dans la strate. À titre d'exemple, Visalli et $a l$. ont développé un modèle de culture 3D de cellules épithéliales primaires de prépuce et de col de l'utérus sur une matrice de collagène avec une lignée de fibroblastes de souris. Suite à l'infection par HSV-1 de ces cultures épithéliales pluristratifiées et pleinement différenciées, les auteurs ont montré que l'infection productive de HSV-1 s'établit exclusivement dans les couches les plus basales de l'épithélium. Les modèles de culture 3D de cellules épithéliales génitales ont également permis des avancées considérables dans l'étude des infections avec HPV, puisque le cycle réplicatif de ce virus est fortement dépendant de la différenciation du tissu épithélial hôte. L'infection des cellules épithéliales est reproduite, soit par l'ensemencement de cellules épithéliales de biopsies de patients infectés, soit par la transfection des cellules épithéliales avec l'ADN génomique d'un virus HPV ou encore avec des lignées épithéliales immortalisées par HPV [67]. Dans ce dernier cas, la différenciation de l'épithélium conduit à la formation de néoplasies de différents grades, similaires à ce qui est observé in vivo, permettant son utilisation pour étudier la progression cancéreuse. Ce modèle permet également de reproduire les différentes étapes du cycle viral de HPV, dont la maintenance épisomale du génome viral, l'amplification du génome viral et la différenciation des cellules épithéliales qui dépend de l'expression de gènes viraux. Il a permis, pour la première fois, la production in vitro de virions $\operatorname{HPV}[68,69]$. Quelques études ont ainsi pu utiliser ce modèle pour tester l'efficacité de molécules thérapeutiques contre l'infection HPV [38]. 
Grâce à un modèle plus intégratif de culture organotypique d'explants de col de l'utérus (exocol et endocol), Horbul et al. ont démontré que l'infection des cellules épithéliales génitales par HSV-2 est cytolytique, induit l'inflammation du tissu mucosal et, de ce fait, favorise l'infection par VIH-1 des muqueuses génitales [70]. Une limite non négligeable de ce type de modèle pour l'étude de l'infection d'un épithélium pluristratifié est la perte de stratification de l'épithélium après quelques jours (e.g. moins de six jours pour l'épithélium d'exocol dans étude de Horbul et al.).

\section{Analyse des mécanismes de franchissement de la barrière épithéliale en absence d'infection productive des cellules épithéliales}

De nombreux virus sexuellement transmissibles peuvent traverser la barrière épithéliale sans l'infecter de façon productive. Comme indiqué dans la section « Modes d'infection des muqueuses exposées aux sécrétions génitales », diverses stratégies ont été mises en place par ces virus pour accéder aux cellules cibles présentes en sousmuqueux. Dans cette partie, nous nous intéresserons aux modèles in vitro qui ont été mis en place pour étudier ces différents mécanismes de franchissement de la barrière épithéliale.

\section{Analyse de la formation de brèches épithéliales}

L'accès le plus courant et le plus aisé aux cellules cibles de la muqueuse est l'infiltration du virus dans des brèches de l'épithélium. Ces brèches peuvent être provoquées mécaniquement par des rapports intimes, conséquentes d'une infection génitale préalable, ou générées par le virus luimême. Ainsi, l'inflammation de la muqueuse induite par une infection bactérienne ou virale se traduit par un afflux de cellules immunitaires et de cytokines pro-inflammatoires, lesquelles peuvent altérer la barrière épithéliale, rendant ainsi les cellules muqueuses sous-épithéliales accessibles à d'autres agents pathogènes. Certains virus tels que le virus de l'herpès altèrent directement les cellules épithéliales induisant des ulcérations herpétiques. Nazli et al. ont ainsi étudié la capacité du VIH-1 à générer des brèches $[71,72]$. Pour cela, un modèle de cellules épithéliales primaires polarisées d'endomètre et de col de l'utérus cultivées sur matrigel et des cellules T84 (lignée cellulaire intestinale) polarisées a été utilisé. Les auteurs ont montré que l'exposition à des particules de VIH-1 altère l'intégrité de ces monocouches épithéliales et se traduit par une baisse de la résistance trans-épithéliale, une perte de l'expression des protéines de jonction et une perméabilité accrue de la barrière épithéliale au dextran. Grâce à ces modèles simplifiés de barrière épithéliale, le mécanisme de cette altération a pu être appréhendé, et des expériences de neutralisation ont démontré que la protéine d'enveloppe du virus (gp120) génère une altération de la barrière épithéliale via l'induction de la sécrétion de $\mathrm{TNF} \alpha$ par les cellules épithéliales [71]. Dans cette étude, on note que les profils d'expression cytokiniques diffèrent grandement selon le modèle cellulaire, immortalisé ou primaire, soulignant que l'interprétation des résultats obtenus avec des modèles de cultures de cellules immortalisées est sujette à caution. Comme dans toutes les études in vitro, il est important également, dans l'interprétation des résultats, de prendre en compte la dose et la souche de virus utilisées pour déterminer si elles peuvent correspondre à une exposition réaliste.

\section{Analyse de la capture de particules virales par les cellules immunitaires muqueuses}

Un autre moyen pour les pathogènes d'accéder aux cellules cibles sous-épithéliales est leur capture par les cellules dendritiques ou les cellules de Langerhans enchâssées dans les épithélia pluristratifiés ou présentes juste au pôle basal des épithélia monostratifiés. Ces cellules expriment des récepteurs de surface cellulaire tels que des héparines sulfate protéoglycanes (HSPG), des lectines de type C et des intégrines qui permettent la capture de particules de VIH sans infection productive de ces dernières.

Afin d'étudier ce phénomène au sein d'un épithélium monostratifié, Cavarelli et al. ont développé deux modèles [37]. Le premier modèle consiste en une co-culture sur insert semi-perméable d'une lignée épithéliale colorectale Caco2 polarisée et de cellules dendritiques cultivées sous l'insert, au pôle basal des cellules épithéliales (la mise en place d'un tel système est décrite sur la figure 2). Le virus est ensuite déposé à la surface apicale des cellules épithéliales. Après quelques heures d'exposition, la barrière épithéliale est observée en microscopie confocale, ce qui permet une visualisation en profondeur de la couche de cellules. Ce modèle a permis de montrer que le VIH induit une migration des cellules dendritiques vers le côté apical de l'épithélium. On peut ici s'interroger sur la pertinence physiologique de ce modèle simplifié, les cellules dendritiques migrantes ayant été isolées à partir du sang et non originaire d'un tissu. Toutefois, ces observations ont été validées grâce à un modèle plus intégratif de culture d'explant de tissu colorectal. Dans ce modèle, l'exposition polarisée de l'épithélium colorectal à des particules de VIH-1 induit également l'attraction de cellules présentatrices $d$ ' antigènes muqueuses vers le pôle apical des cellules épithéliales, ainsi que la capture de particules virales par ces mêmes cellules [37].

Afin d'analyser l'implication des cellules dendritiques enchâssées dans les épithélia pluristratifiés dans la transmission virale, Bomsel et al. ont, quant à eux, développé un modèle de culture organotypique de muqueuse de prépuce $[12,73]$. Grâce à ce modèle, les auteurs ont observé, 
en microscopie à fluorescence, que l'exposition polarisée de la muqueuse épithéliale interne du prépuce avec des leucocytes sanguins fortement infectés par une souche de VIH-1 induit une modification rapide de la distribution spatiale des cellules de Langerhans intraépithéliales, ces dernières se rapprochant de la surface épithéliale, ainsi que la formation de conjugués (cellules de Langerhanslymphocytes $\mathrm{T}$ ) au niveau desquels ont été observées des particules virales et ont pu décortiquer les mécanismes moléculaires impliqués. Les résultats obtenus, grâce à ce modèle, suggèrent que les cellules de Langerhans intraépithéliales du prépuce interne sont les cibles initiales de la transmission au niveau du prépuce interne. Toutefois, la limite majeure des modèles « explants » pluristratifiés est la perte rapide de l'intégrité structurale et morphologique du tissu et, après quelques heures, la migration hors du tissu des cellules immunes intraépithéliales, ce qui rend impossible la distinction entre les cellules d'origine intraépithéliale ou les cellules immunes du stroma. L'observation d'évènements d'infection plus tardifs nécessite donc la mise en place d'autres modèles, plus stables mais moins proches des conditions in vivo. Dans ce but, les modèles de reconstruction 3D de muqueuse pluristratifiée de vagin $[39,40]$ et de prépuce [12] dans lesquels ont été intégrées des cellules de Langerhans sont particulièrement appropriés et permettent d'évaluer le rôle des cellules dendritiques à plus long terme dans la mise en place de l'infection de ces muqueuses. À titre d'exemple, Sivard et al. ont intégré, dans leur modèle de reconstruction $3 \mathrm{D}$ de muqueuse vaginale, des cellules de Langerhans différenciées à partir de cellules CD34+ progénitrices des cellules hématopoḯtiques, isolées de cordon ombilical [40]. Dans ce système, les auteurs ont pu mettre en évidence, à 48 heures post-infection, la présence d'ADN viral dans les cellules de Langerhans et l'inhibition complète de leur infection en présence d'un inhibiteur de la RT.

Par ailleurs, Hladik et al. ont développé un modèle original de culture de feuillet épithélial de la muqueuse vaginale $[74,75]$. Dans ce modèle, la couche épithéliale pluristratifiée est séparée de la lamina propria par microdissection associée à un traitement à l'EDTA. L'intérêt majeur de ce modèle est qu'il permet l'étude ciblée de l'infection des cellules immunes intraépithéliales en s'affranchissant du problème d'émigration des cellules immunitaires hors du tissu puisque, en l'absence de sous-muqueuse, les seules cellules à émigrer sont originaires de la couche épithéliale. Hladik et al. ont ainsi pu mettre en évidence l'attachement et l'entrée de particules virales dans les lymphocytes T CD4+ et cellules de Langerhans intraépithéliales de la muqueuse vaginale par microscopie confocale [74]. Quelques années plus tard, cette même équipe a amélioré ce système en polarisant l'infection à la face apicale du feuillet épithélial.
De cette façon, ils ont démontré, en mettant en évidence l'absence d'intégration de l'ADN proviral, que les cellules de Langerhans intraépithéliales ne sont pas capables d'infection productive par le VIH-1, mais participent à la dissémination virale comme l'attestent les tests d'infection sur une co-culture de lymphocytes T CD4+ [75].

\section{Analyse du passage de virus par transcytose}

La transcytose consiste au transport polarisé de virus à l'intérieur de cellules épithéliales, du pôle apical vers le pôle basal, sans infection productive de la cellule hôte. Le virus endocyté par les cellules épithéliales peut provenir d'une source de virus libre ou bien de particules virales relarguées par des cellules infectées qui forment des synapses virologiques au pôle apical des cellules épithéliales. Ce mécanisme de transmission virale au niveau des muqueuses génitales ou colorectales a été décrit pour la première fois pour le VIH-1 in vitro par Bomsel en 1997 [76]. Le passage de l'épithélium par transcytose a été confirmé pour VIH1 et d'autres rétrovirus tels que le HTLV-1 par ce même auteur et d'autres équipes dans d'autres modèles in vitro ou ex vivo, mais n'a jamais été mis en évidence in vivo [46, 77-83]. La transcytose du VIH-1 a ainsi été montrée dans des cultures polarisées de monocouches de cellules épithéliales immortalisées dérivées d'intestin (I407), de côlon (HT29, Caco2), d'endomètre (HEC-1) et primaires de cellules vaginales et endocervicales en monocouches, exposées à des particules virales de VIH-1 ou des cellules leucocytaires infectées VIH-1 pendant un temps court, insuffisant à l'infection productive des cellules épithéliales. Le passage de virus à travers la barrière épithéliale a été mis en évidence dès 30 minutes d'exposition, par mesure de la protéine virale p24 dans le surnageant de culture basale, par test d'infectivité sur des cellules reportrices, ou par observation en microscopie électronique de l'infection des cellules. La cinétique d'internalisation des particules virales a été évaluée par mesure de la protéine de capside virale p24 dans les cellules épithéliales lysées. Le passage viral est inhibé à $4{ }^{\circ} \mathrm{C}$ et par la dépolymérisation irréversible des microtubules. La mise en évidence de la transcytose de particules virales nécessite impérativement de s'assurer de l'étanchéité de la couche épithéliale, par le contrôle du maintien de la résistance transépithéliale, l'absence du passage paracellulaire de marqueurs extracellulaires (e.g. $\left[{ }^{14} \mathrm{C}\right]$ inulin ou FITC-BSA) et le maintien de l'expression de protéines de jonctions telles que ZO-1. Cela permet d'exclure le passage de particules virales par un mécanisme paracellulaire, c'est-à-dire entre les cellules épithéliales. Malgré quelques discordances liées à l'utilisation de protocoles d'infections différents (concentration et temps d'exposition du virus), ces études ont permis de conclure 
sur la plus grande efficacité du mécanisme de transcytose lorsque les cellules épithéliales sont exposées à des cellules infectées plutôt qu'à des particules virales libres et sur la formation d'une synapse virale entre la cellule leucocytaire infectée et la cellule épithéliale [76, 80, 82]. Bien que ce mécanisme de transmission virale ait été clairement mis en évidence in vitro dans des modèles de cultures cellulaires monostratifiées, son existence in vivo, ou tout au moins dans des modèles ex vivo plus physiologiques, reste à démontrer. La confirmation de la transcytose sur des modèles plus intégratifs d'explants de muqueuse, comme suggérée par les résultats de Shen et al. dans des cultures d'explants rectaux ou vaginaux $[4,46]$, est compliquée par la possibilité du transport du virus par les cellules « cheval de Troyes » présentes dans la muqueuse ou enchâssées entre les cellules épithéliales, telles que des macrophages ou des cellules dendritiques. Ce biais peut être contourné par l'utilisation de modèles intégratifs moins proches de l'in vivo mais plus contrôlés, tels que les modèles de reconstruction $3 \mathrm{D}$, où l'on peut sélectionner les types cellulaires mis en présence en fonction de la question abordée. Ainsi, Bouschbacher et al. montrent l'absence de passage de particules virales de VIH-1 à travers l'épithélium vaginal pluristratifié dans un modèle de reconstruction $3 \mathrm{D}$, que ce soit en présence ou en l'absence de cellules de Langherans enchâssées dans l'épithélium [39]. Greenhead et al. ont, quant à eux, développé un modèle de culture de feuillet de l'épithélium ectocervical pour évaluer la possibilité de transcytose dans la muqueuse génitale pluristratifiée. Après isolation enzymatique, la couche épithéliale est mise en culture et exposée de façon polarisée à des particules virales libres de VIH1 ou des cellules infectées. Aucun évènement d'infection n'a été détecté dans le surnageant de culture ou dans les cellules épithéliales [57]. Ces deux études suggèrent donc l'absence de transcytose du VIH-1 à travers les épithélia génitaux pluristratifiés. Toutefois, il n'est pas exclu que les étapes de digestion enzymatique nécessaires à la mise en place de ces modèles puissent avoir engendré une perte d'expression de certains marqueurs membranaires nécessaires à l'attachement et l'internalisation des particules virales.

\section{Analyse de la transmigration de cellules infectées à travers la barrière épithéliale}

La transmigration correspond au passage actif de cellules infectées entre les cellules épithéliales sans qu'il y ait rupture de la barrière. Les modèles les plus simples et rapides à mettre en œuvre pour étudier ce mécanisme de transmission virale sont les lignées épithéliales monostratifiées polarisées [24, 84, 85]. Ainsi, Lawrence et al. ont mis en évidence les capacités de transmigration des monocytes et, dans une moindre importance, des lymphocytes T CD4+ sur une monocouche polarisée de cellules immortalisées endométriales (HEC-1) [24]. Pour cela, des monocytes ou lymphocytes isolés du sang, infectés in vitro et marqués, sont déposés sur la monocouche épithéliale polarisée et la transmigration est évaluée après 24 heures par comptage du nombre de cellules marquées récupérées dans le surnageant basal du système ou par mesure de l'intensité de fluorescence de ce surnageant. L'avantage majeur de ce modèle simplifié de cellules épithéliales immortalisées polarisées est qu'il permet de facilement appréhender les mécanismes moléculaires et les facteurs environnementaux impliqués dans l'adhésion des cellules transmigrantes aux cellules épithéliales et leur passage sous-épithélial. Ainsi, Lawrence et al. montrent dans leur modèle de HEC-1 polarisées que le liquide séminal a un effet inhibiteur sur la transmigration de leucocyte à travers la barrière épithéliale. Cet effet est associé à une augmentation de l'expression des protéines des jonctions ZO-1 entre les cellules épithéliales et à une augmentation des capacités d'adhésion des leucocytes aux cellules épithéliales [24]. Une étude plus ancienne avait déjà mis en évidence une augmentation des capacités d'adhésion d'une lignée lymphocytaire aux barrières épithéliales cervicales et intestinales (respectivement lignées MT180 et I407 non polarisées) exposées au liquide séminal [86]. Dans le même modèle de cellules HEC1 polarisées qu'utilisent Lawrence et al., Carreno et al. ont, quant à eux, validé, à l'aide d'anticorps monoclonaux, l'implication de deux molécules d'adhésion exprimées à la surface épithéliale, CD50 et CD102, dans la transmigration des cellules monocytaires et montré que l'environnement pro-inflammatoire du tractus génital féminin, mimé expérimentalement par l'ajout de cytokines pro-inflammatoires dans le milieu de culture, favoriserait l'expression de ces molécules d'adhésion et, ainsi, la transmigration de monocytes infectés à travers la barrière épithéliale [84]. Toutefois, bien que ce modèle simplifié représente un bon modèle d'approche ou de validation moléculaire, il reste assez éloigné de la situation in vivo et fait abstraction de l'influence du contexte tissulaire sur l'expression des molécules d'adhésion par les cellules épithéliales.

À cela, le modèle « explant » constitue une alternative plus physiologique. Dans ce modèle, la transmigration de cellules préalablement marquées par un fluorochrome et déposées de façon polarisée à la surface épithéliale de l'explant peut être mise en évidence dans le tissu par microscopie ou en cytométrie de flux après dissociation enzymatique du tissu [41, 42]. Dans ce dernier cas, la présence de cellules marquées dans la suspension cellulaire atteste de la pénétration des cellules au sein du tissu. La limite principale de ce modèle est qu'il ne permet de maintenir l'intégrité de la barrière épithéliale qu'un temps limité, variable selon l'origine 
tissulaire (selon les études et les conditions de culture environ 24 heures pour le tissu colorectal, 48 heures pour l'exocol, quatre à six jours pour l'endocol). L'utilisation de ce modèle pour observer des évènements de transmigration nécessite donc de s'assurer de façon rigoureuse de la conservation de l'intégrité de la barrière épithéliale le temps nécessaire à la transmigration (e.g. vérification de l'absence de passage de molécules extracellulaires marquées). Ainsi, dans des modèles de culture d'explant d'exocol et d'endocol humains, Maher et al. ont observé en microscopie l'infiltration de leucocytes séminaux dans les couches les plus externes de l'épithélium pluristratifié de l'exocol, mais l'absence d'infiltration dans l'épithélium endocervical, les cellules séminales étant retenues dans les sécrétions de la muqueuse qui semblent donc jouer un rôle protecteur face à l'infection dans leur modèle [42].

\section{Étude de l'infection des cellules cibles sous épithéliales et de la réponse à l'infection dans les muqueuses}

Outre les mécanismes de franchissement de la barrière épithéliale, il est primordial de comprendre comment le virus va s'installer et disséminer dans la muqueuse (analyse des cellules cibles de l'infection, de leur proportion, de leur localisation dans le tissu et de leur susceptibilité à l'infection), ainsi que les conséquences de cette infection (effet cytopathique, mise en place d'une réponse immune locale antivirale et pro-inflammatoire), dans le but de mettre au point des stratégies pour prévenir l'infection.

Afin d'étudier la permissivité à l'infection VIH-1 des différentes populations cellulaires, épithéliales et stromales, des tissus génitaux féminins, Howell et al. ont isolé par digestion enzymatique et mis en culture chaque population cellulaire. L'infection des cellules a été déterminée à cinq jours de culture par mesure de la protéine virale p24 relarguée dans le surnageant de culture et l'observation en immunofluorescence de cette même protéine virale dans les cellules [56]. Il faut toutefois être prudent dans l'analyse de la permissivité à l'infection de cellules isolées car les multiples étapes de digestion enzymatique et la culture hors contexte tissulaire sont susceptibles de modifier l'expression des récepteurs d'entrée virale et d'autres molécules déterminantes dans l'aptitude à l'infection des cellules. Cette équipe a également développé un modèle de culture de sections de 30-70 $\mu$ de tissu [56]. Ce modèle permet de conserver en culture a minima l'architecture tissulaire, mais l'analyse de la nature des cellules infectées en immunofluorescence est compliquée par l'épaisseur de la couche cellulaire.

Le modèle d'explant, polarisé ou non, constitue un modèle de choix pour étudier la susceptibilité à l'infection des cellules muqueuses dans la mesure où le contexte tissulaire original et l'environnement cytokinique présent in vivo peuvent être préservés le temps nécessaire à l'observation de l'infection du tissu. Nous citerons, de façon non exhaustive, plusieurs modèles d'explants développés pour analyser les capacités d'infection des cellules des muqueuses génitales féminines [4, 42, 43, 57, 87, 88], du tractus génital masculin $[15,88,89]$ ou de la muqueuse colorectale $[41,47]$. Dans ces études, l'infection du tissu par VIH-1 ou d'autre virus est déterminée par mesure quantitative en PCR du nombre de copies de génome viral présent dans le tissu $[4,47,88]$, ou mesure de protéines virales relarguées dans le surnageant de culture (e.g. p24 pour VIH-1) [15, 47, 57, 89]. L'identification de la nature des cellules infectées peut être réalisée par analyse en cytométrie de flux après dissociation enzymatique du tissu [41, 87], co-marquage immunohistochimique avec des marqueurs de protéines cellulaires et de protéines virales $[4,42,57,87]$ ou par la détection du génome viral dans les cellules muqueuses par hybridation in situ combinée à un marquage immunohistochimique pour identifier la cellule infectée [12, 15, 43, 51, 52, 88, 90]. L'identification des cellules infectées peut également être facilitée en inoculant le tissu avec un virus CMV modifié exprimant une protéine fluorescente (e.g. CMV-GFP [87]). Dans ce modèle, il est possible de mimer l'activation des cellules immunes muqueuses [57, 89], ce qui augmente l'infectiosité des cellules muqueuses selon le tropisme de la souche virale [57]. Certains types cellulaires, en particulier les cellules de Langerhans et cellules dendritiques, ayant tendance à migrer hors de l'explant [89], il peut être nécessaire de collecter ces cellules pour analyser leur infection. Dans les modèles d'explants non polarisés [47, 57, 87, 89], l'infection des cellules muqueuses sous-épithéliales est facilitée par une exposition au virus par immersion des explants, l'infection initiale n'est ainsi pas limitée à la face épithéliale du tissu. L'avantage majeur de ces modèles d'explants non polarisés est qu'ils permettent de s'intéresser aux évènements précoces d'infection des muqueuses dans un modèle intégratif, en outrepassant l'étape de passage de la barrière épithéliale qui nécessite la mise au point de modèles plus complexes avec le maintien de l'étanchéité et de l'intégrité d'un ou de plusieurs couches épithéliales. Récemment, ces modèles ont été utilisés pour évaluer l'effet de l'imprégnation hormonale du tractus génital féminin sur la permissivité à l'infection VIH-1 [91-93]. Saba et al. ont ainsi mis en évidence une réplication VIH1 accrue dans les tissus cervicaux de femmes en phase sécrétrice du cycle menstruel qui est dominée par la progestérone [92]. Ces modèles permettent également d'analyser l'activation immunitaire induite par l'infection, en mesurant la production de cytokines produites par le tissu et relarguées dans le surnageant de culture ou en déterminant le 
phénotype des cellules immunitaires muqueuses en cytométrie de flux ou immunohistochimie, et de tester l'effet cytopathogène du virus sur la muqueuse [89].

Les modèles d'explants polarisés, pour lesquels l'inoculation virale est restreinte à la surface épithéliale de l'explant, apportent, lorsqu'ils sont utilisés dans la limite de leur validité, une réponse plus physiologique aux capacités de transmission de l'infection aux cellules muqueuses $[4,12,41-43,88]$. À titre d'exemple, Shen et al. ont utilisé des modèles d'explants polarisés de muqueuses vaginales et intestinales pour étudier la permissivité au VIH-1 des macrophages muqueux. Alors que les macrophages intestinaux restent non permissifs à l'infection, l'infection des macrophages vaginaux a été détectée dès 30 minutes d'exposition à une souche de tropisme R5, et cette différence de permissivité a été mise en relation avec une différence phénotypique d'expression de récepteurs de la réponse immune innée (CD14, CD16, CD34, CD64, CD89) et des corécepteurs à l'entrée du VIH-1 (CCR5, CXCR4) dans les cellules dans les deux tissus [4]. Toutefois, comme nous l'avons précédemment mentionné, l'intégrité de l'épithélium ne peut être maintenue qu'un temps limité in vitro, en particulier pour les épithélia monostratifiés du côlon. L'atout physiologique de ce modèle pour détecter l'infection des cellules muqueuses doit de ce fait être systématiquement validé par la vérification de l'intégrité de l'épithélium au moment de la détection virale.

La reproductibilité des résultats obtenus en modèle « explant » est souvent compliquée par la variabilité inter-donneur des tissus en termes, par exemple, de statut hormonal et inflammatoire, des antécédents de maladies sexuellement transmissibles, ou encore de différences de proportions dans les populations de cellules cibles entre les différents fragments de tissu. Ainsi, dans leur modèle d'explants cervicaux polarisés, Maher et al. attribuent l'absence de détection de cellules infectées dans deux de leurs huit explants à une différence d' activation immunitaire des cellules muqueuses chez les donneurs [42].

\section{Test in vitro de stratégies antivirales}

Les modèles in vitro et ex vivo de muqueuses exposées à des virus sexuellement transmissibles constituent un outil incontournable pour l'évaluation préclinique de l'innocuité, de l'efficacité et de la formulation des stratégies antivirales locales. En effet, il est primordial de s'assurer que les composés testés n'induisent aucune toxicité tissulaire, laquelle pourrait fragiliser la barrière épithéliale ou induire une inflammation de la muqueuse. On cherche également à tester l'efficacité des molécules antivirales dans des modèles qui permettront de mimer les conditions phy- siologiques où l'infection présente un plus fort risque, à savoir lorsque la barrière épithéliale est compromise et/ou en conditions inflammatoires.

La majorité des études qui ont été réalisées à ce jour avaient pour objectif de tester des molécules anti-VIH-1, que ce soit dans des modèles de culture de cellules épithéliales primaires ou lignées, de reconstruction 3D de l'épithélium muqueux ou d'explants tissulaires [37, 89, 94100]. L'approche couramment utilisée consiste à exposer les muqueuses à la molécule antivirale testée en même temps ou avant une exposition virale. D'une manière générale, l'inhibition de l'infection est évaluée par mesure de protéines virales relarguées dans le milieu de culture (p24 dans le cas du VIH-1), quantification du génome viral dans les cellules muqueuses ou surnageant de culture, test de l'infectiosité des cellules émigrant des explants tels que des cellules dendritiques sur cellules reportrices permissives à l'infection ou encore observation histologique de l'atténuation de l'effet cytopathogène du virus. L'innocuité des molécules testées sur l'intégrité de la muqueuse est évaluée par observation histologique et test de viabilité MTT ou dosage de la LDH. Les limites et les avantages de ces différents modèles restent les mêmes que pour l'analyse de la transmission virale ou de la permissivité à l'infection des cellules muqueuses. Dans ce paragraphe, nous analyserons, à travers quelques études, l'intérêt de ces différents modèles pour le screening préclinique des molécules antivirales.

Les modèles de reconstruction 3D de la muqueuse épithéliale à l'interface air-liquide ( $c f$. section « Reconstructions 3D de muqueuses pluristratifiées ») sont particulièrement adaptés au test de molécules antivirales contre des virus infectant les cellules épithéliales tels que les virus herpes alpha ou HPV [38]. Dans un modèle de reconstruction 3D de muqueuse épithéliale à partir de kératinocytes de prépuces de nouveau-nés infectés par les virus herpes alpha HSV-1, HSV-2 et le virus varicelle-zona (VZV), Andrei et al. [94] ont validé l'activité antivirale de différentes molécules de référence (e.g. acyclovir). Ce modèle a pour objectif de remédier à l'absence de modèle animal pour tester l'efficacité des nouvelles drogues anti-varicelle-zona. Toutefois, dans leur étude, Andrei et al. ajoutent les composés antiviraux dans le milieu de culture, ce qui revient à mimer une distribution par voix systémique. Une amélioration serait de tester l'activité antivirale de ces drogues dans un système mimant une application muqueuse locale, avec un ajout des molécules antivirales à la surface épithéliale de la muqueuse. Cole et al. ont démontré l'activité anti-VIH des rétrocyclines, une famille de peptides antimicrobiens naturellement exprimés dans le vagin et col de l'utérus, dans un modèle commercial de reconstruction 3D de l'épithélium vaginal dans lequel sont insérées des cellules de Langerhans (MatTek) [99]. 


\begin{tabular}{|c|c|c|c|c|}
\hline But de l'étude & Modèles utilisés & Réf & Avantages & Limites \\
\hline $\begin{array}{l}\text { Étude de la provenance des virus } \\
\text { dans les secrétions génitales }\end{array}$ & Culture organotypique & {$\left[\begin{array}{l}{[50]} \\
{[51]} \\
{[52]}\end{array}\right.$} & Modèle intégratif permettant analyse de la permissivité des cellules muqueuses originales & s Pas de corrélat possible tissu/sperme \\
\hline \multirow{4}{*}{$\begin{array}{l}\text { Étude des mécanismes d'infection } \\
\text { de la barrière épithéliale }\end{array}$} & Lignée de cellules épithéliales & $\begin{array}{l}{[55]} \\
{[58]} \\
{[60]}\end{array}$ & $\begin{array}{l}\text { Modèle bien caractérisée et standardisé, peu coûteux et peu fragile } \\
\text { Modulation de l'expression génique facilement réalisable }\end{array}$ & $\begin{array}{l}\text { Morphologie et caractéristiques biochimiques pouvant différer des cellules primaires (composition } \\
\text { en lipides, en protéines et glycosylation...) pouvant moduler les mécanismes d'entrée virale } \\
\text { et d'infection des cellules }\end{array}$ \\
\hline & $\begin{array}{l}\text { Culture primaire de cellules } \\
\text { épithéliales }\end{array}$ & $\begin{array}{l}{[54]} \\
{[55]} \\
{[56]} \\
{[57]}\end{array}$ & Cellules isolées de tissu & $\begin{array}{l}\text { Utilisation enzymes de digestion pour isolement: risque de modification de l'expression } \\
\text { de proteines membranaires, potentiels récepteurs à l'entrée virale } \\
\text { Après isolement les cellules sont plus fragiles que des cellules issues de lignée }\end{array}$ \\
\hline & \begin{tabular}{|c|} 
Système de reconstruction \\
$3 \mathrm{D}$
\end{tabular} & [65] & $\begin{array}{l}\text { Modèle de choix pour étude de l'infection HSV ou HPV qui nécessitent un épithélium } \\
\text { pluristratifié différencié }\end{array}$ & Plusieurs semaines pour la mise en place du modèle \\
\hline & $\begin{array}{c}\begin{array}{c}\text { Culture organotypique } \\
\text { polarisée }\end{array} \\
\end{array}$ & [70] & Modèle le plus intégratif & Perte rapide de la stratification de l'epithélium \\
\hline \multicolumn{5}{|c|}{ Analyse des mécanismes de franchissemement de la barrière (sans infection productive des cellules épithéliales) } \\
\hline \multirow{2}{*}{ par formation de brèches } & Lignée de cellules épithéliales & \multirow{2}{*}{ [71] } & \multirow{2}{*}{$\begin{array}{l}\text { Polarisation des cellules épithéliales, permet d'appréhender les mecanismes d'altération } \\
\text { de la barrière }\end{array}$} & \multirow{2}{*}{$\begin{array}{l}\text { Profils d'expressions cytokines divergenants entre lignées cellulaires et cellules primaires - } \\
\text { prudence dans l'interprétation des résultats }\end{array}$} \\
\hline & \begin{tabular}{|c|}
$\begin{array}{c}\text { Culture primaire de cellules } \\
\text { epithéliales }\end{array}$ \\
\end{tabular} & & & \\
\hline \multirow{3}{*}{$\begin{array}{l}\text { par capture des particules virales } \\
\text { par les cellules immunes } \\
\text { muqueuses }\end{array}$} & Co-culture cellulaire & [35] & $\begin{array}{l}\text { Étude ciblée des intéractions entre la barrière épithéliale et différents types cellulaires } \\
\text { présents en sous-muqueux }\end{array}$ & $\begin{array}{l}\text { Pas d'étude en épithélium pluristratifié possible } \\
\text { Origine lignée ou sanguine des cellules du modèle }\end{array}$ \\
\hline & $\underline{\text { Reconstructions 3D }}$ & $\begin{array}{l}{[12]} \\
{[39]} \\
{[40]} \\
\end{array}$ & \begin{tabular}{|l} 
Choix des cellules insérées dans l'épithélium pour étude mécanistique \\
Bon maintien des cellules immunes dans la couche épithéliale pluristratifiée \\
\end{tabular} & $\begin{array}{l}\text { Mélange de cellules primaires et immortalisées avec des caractéristiques différentes des cellules } \\
\text { muqueuses originales }\end{array}$ \\
\hline & $\begin{array}{l}\text { Culture organotypique } \\
\text { polarisée }\end{array}$ & $\begin{array}{l}{[12]} \\
{[35]} \\
{[73]} \\
\end{array}$ & $\begin{array}{l}\text { Modèle le plus intégratif } \\
\text { Respect de l'architecture et présence des différents types cellulaires dans des proportions } \\
\text { proches du vivo } \\
\text { Cellules muqueuses authentiques }\end{array}$ & serte rapide de l'intégrité de l'épithélium et émigration des cellules immunes hors du tissus \\
\hline \multirow{4}{*}{ par transcytose } & Lignée de cellules épithéliales & $\begin{array}{l}{[74]} \\
{[77]} \\
{[78)} \\
{[810} \\
\end{array}$ & Polarisation des cellules épithéliales & Morphologie et caractéristiques biochimiques différentes du vivo \\
\hline & $\begin{array}{c}\text { Culture primaire de cellules } \\
\text { épithéliales }\end{array}$ & [79] & $\begin{array}{l}\text { Cellules primaires } \\
\text { Polarisation selon les types de cellules épithéliales }\end{array}$ & $\begin{array}{l}\text { Dissociation enzymatique pour la mise en place du modèle : risque de perte de marqueurs } \\
\text { membranaires nécessaires à l'attachement des cellules infectées et/ou particules virales } \\
\text { Polarisation plus difficile }\end{array}$ \\
\hline & Reconstructions 3D & $\begin{array}{l}{[39]} \\
{[57]} \\
\end{array}$ & $\begin{array}{l}\text { Adapté à l'analyse des épithélium pluristratifiés } \\
\text { Sélection des types cellulaires inclus dans le modèle }\end{array}$ & Plusieurs semaines pour la mise en place du modèle \\
\hline & $\begin{array}{l}\text { Culture organotypique } \\
\text { polarisée }\end{array}$ & $\begin{array}{l}{[4]} \\
{[46]}\end{array}$ & $\begin{array}{l}\text { Modèle le plus intégratif } \\
\text { Possibilité de culture de feuillet de l'épithélium pour éliminer cellules « cheval de Troyes » }\end{array}$ & $\begin{array}{l}\text { Possibilité du transport du virus par les cellules « cheval de Troyes » présentes dans la muqueuse } \\
\text { ou dans l'épithélium qui complique l'interprétation des résultats }\end{array}$ \\
\hline \multirow{2}{*}{$\begin{array}{l}\text { par transmigration de cellules } \\
\text { infectées }\end{array}$} & Lignée de cellules épithéliales & \begin{tabular}{|l|l|}
{$[22]$} \\
{$[82]$} \\
{$[83]$} \\
\end{tabular} & $\begin{array}{l}\text { Polarisation simple et rapide } \\
\begin{array}{l}\text { Appréhension facile des mécanismes moléculaires et des facteurs environnementaux } \\
\text { impliqués }\end{array} \\
\end{array}$ & Pas de contexte tissulaire \\
\hline & $\begin{array}{l}\text { Cultures organotypiques } \\
\text { polarisée }\end{array}$ & $\begin{array}{l}{[41]} \\
{[42]}\end{array}$ & Modèle intégratif & Maintien limité de l'intégrité de la barrière épithéliale \\
\hline \multirow[b]{2}{*}{$\begin{array}{l}\text { Étude de l'infection des cellules } \\
\text { cibles sous épithéliales et de la } \\
\text { réponse à l'infection des } \\
\text { muqueuses }\end{array}$} & $\begin{array}{l}\text { Culture primaire de cellules } \\
\text { muqueuses isolées }\end{array}$ & {$[56]$} & Cellules muqueuses originales & $\begin{array}{l}\text { Étape de digestion enzymatique et culture hors contexte tissulaire qui peuvent modifier } \\
\text { ''expression de marqueurs membranaires importants pour l'entrée virale et l'infection des cellules }\end{array}$ \\
\hline & Culture organotypique & $\begin{array}{l}{[4]} \\
{[41]} \\
{[43]} \\
{[47]} \\
{[51]} \\
{[52]} \\
{[85]} \\
{[86]} \\
{[88]} \\
\end{array}$ & $\begin{array}{l}\text { Présence du contexte tissulaire original et environnement cytokinique } \\
\text { Respect de l'architecture et présence des différents types cellulaires dans des proportions } \\
\text { proches du vivo } \\
\text { Possibilité de polariser la transmission virale }\end{array}$ & $\begin{array}{l}\text { Grande variabilité interdonneurs en terme de statut hormonal / inflammation / antécédent de } \\
\text { maladies sexuellement transmissibles / populations de cellules cibles } \\
\text { Variabilité intratissulaire en termes de population cellulaires présentes }\end{array}$ \\
\hline \multirow[b]{2}{*}{$\begin{array}{l}\text { Test in vitro de stratégies anti- } \\
\text { virales }\end{array}$} & Reconstruction 3D & $\begin{array}{l}{[92]} \\
(93]\end{array}$ & $\begin{array}{l}\text { Particulièrement adapté pour l'étude de molécules antivirales ciblant les virus infectant } \\
\text { les cellules épithéliales }\end{array}$ & $\begin{array}{l}\text { Plusieurs semaines pour la mise en place du modèle } \\
\text { Mélange de cellules primaires et immortalisées avec des caractéristiques différentes des cellules } \\
\text { muqueuses originales }\end{array}$ \\
\hline & $\frac{\text { Culture organotypique }+/-}{\text { polarisée }}$ & {$[47]$} & $\begin{array}{l}\text { Polarisation permet le test d'une application locale de molécules antivirales formulées } \\
\text { Possibilité de challengeex vivo }\end{array}$ & $\begin{array}{l}\text { Perte rapide de la stratification de l'épithélium } \\
\text { Grande variabilité interdonneurs en terme de statut hormonal / inflammation / antécédent de } \\
\text { maladies sexuellement transmissibles / populations de cellules cibles } \\
\text { Variabilité intratissulaire en termes de population cellulaires présentes }\end{array}$ \\
\hline
\end{tabular}

Figure 3. Tableau synthétique des modèles utilisés pour répondre aux différentes questions et de leurs avantages et limites propres à chaque question posée. 
Les explants de tissus cervicaux, vaginaux, colorectaux ou du pénis représentent des modèles de choix pour tester l'activité anti-VIH des microbicides. Les modèles d'explants non polarisés avec exposition aux drogues et infection immergées ont permis de tester les doses efficaces à l'inhibition de l'infection VIH-1 ou HSV-2 de différentes molécules (références dans revue [95]). Grâce à ces modèles, il a été montré que l'inhibition de l'infection VIH1 dans les muqueuses par différents inhibiteurs de l'entrée virale et inhibiteurs non nucléosidiques requiert une dose supérieure de plusieurs $\log 10$ par rapport aux doses requises en test in vitro traditionnel sur cellules reportrices [89, 9698]. Ces modèles ont également permis de démontrer le bénéfice d'une combinaison de molécules dans la composition des microbicides [96, 98].

Bien que contraint par le maintien limité de l'intégrité de l'épithélium en culture, les explants polarisés présentent le net avantage de permettre l'évaluation de l'efficacité des molécules formulées, le plus souvent en gel, avec une application épithéliale mimant ainsi la voie d'entrée naturelle de la molécule testée [100,101]. L'utilisation de ces modèles a ainsi permis de démontrer l'innocuité et l'efficacité de plusieurs inhibiteurs de l'entrée du -1 et de la transcriptase inverse (nucléosidique et non nucléosidique) incorporés dans des hydrogels, et de démontrer un effet protecteur [95]. Ces modèles permettent également de tester l'effet des fluides génitaux (sperme et sécrétions vaginales) sur la distribution et l'efficacité des drogues.

Ces dernières années, un modèle original de culture de muqueuse, utilisé en essai clinique, a été développé [95]. Ce modèle de challenge ex vivo consiste à mettre en culture des biopsies colorectales, cervicales ou vaginales prélevées chez des participants ayant utilisé de façon assidue, pendant une période déterminée, un gel ou anneau vaginal à activité antivirale. La biopsie est ensuite infectée par le VIH-1 ex vivo afin d'évaluer l'efficacité du traitement microbicide. La mise en place de ces essais demande une bonne coordination logistique entre la clinique et le laboratoire, mais permet une évaluation plus physiologique de l'efficacité des microbicides.

\section{Conclusion}

Les nombreux modèles in vitro de muqueuses génitales ou colorectales développés ont permis d'apporter des informations capitales sur les mécanismes d'infection de ces muqueuses par les virus sexuellement transmissibles. Cette variété de modèles est justifiée au regard des multiples mécanismes pouvant conduire à l'infection d'une muqueuse, chaque modèle étant plus particulièrement adapté à l'étude d'un mécanisme en particulier (figure 3). De par leur simplicité et flexibilité de construction (variétés des types cellulaires mis en jeu, souches et doses virales, inclusion de facteurs environnementaux...), ces modèles ont permis d'appréhender le rôle de chaque type cellulaire dans la transmission, de décortiquer la réponse immune innée face à l'infection, l'influence des fluides génitaux (sécrétions vaginales et sperme) ou encore du statut hormonal sur la mise en place de l'infection. Ils sont également aujourd'hui indissociables des études in vivo pour l'élaboration de nouvelles stratégies de prévention locales. Ces modèles in vitro mériteront d'être davantage exploités, notamment pour évaluer l'impact du microbiote local sur l'infectiosité des muqueuses. Plusieurs études cliniques indiquent en effet que la modification du microbiome vaginal ou rectal, appelée dysbiose, influence le risque de transmission des maladies sexuellement transmissibles virales ou bactériennes, avec notamment une augmentation du risque de transmission de plus de $60 \%$ en présence d'un microbiome caractéristique des vaginoses bactériennes [21]. Récemment, un premier modèle de reconstruction de muqueuse épithéliale, permettant à la fois la colonisation par les bactéries du microbiome vaginal et l'étude de la transmission de pathogènes sexuellement transmissibles, a été développé [102]. Ce modèle a permis de montrer que la colonisation de la muqueuse par le microbiome de femmes présentant une vaginose bactérienne est associée à une augmentation de la permissivité à l'infection VIH-1 et une efficacité réduite du microbicide ténofovir [102].

Dernièrement, les procédés de bio-impression en 3D suscitent un vif intérêt de la part des chercheurs en ingénierie tissulaire. La bio-impression utilise les technologies d'impression assistées par ordinateur pour déposer couche par couche ou point par point des cellules, des composants de matrice extracellulaire, des facteurs de croissance, etc., permettant l'arrangement et l'assemblage de structures biologiques vivantes en $2 \mathrm{D}$ ou $3 \mathrm{D}$ avec une reproductibilité élevée. Cette nouvelle technologie, qui représente un enjeu capital pour la médecine régénératrice et réparatrice, pourrait également permettre la fabrication de modèles tissulaires, tels que des muqueuses génitales et colorectales hautement contrôlables et reproductibles pour le test pharmacologique de l'action de molécules antivirales [103]. Bien que pour l'heure les modèles tissulaires développés ne reproduisent pas de façon satisfaisante la complexité tissulaire [103], il est probable qu'à terme le développement de la bio-impression pourra supplanter une grande partie des modèles in vitro existants.

\section{Références}

1. Nguyen PV, Kafka JK, Ferreira VH, Roth K, Kaushic C. Innate and adaptive immune responses in male and female reproductive tracts in homeostasis and following HIV infection. Cell Mol Immunol $2014 ; 11: 410-27$. 
2. Shattock RJ, Moore JP. Inhibiting sexual transmission of HIV-1 infection. Nat Rev Microbiol $2003 ; 1: 25-34$

3. Trifonova RT, Lieberman J, van Baarle D. Distribution of immune cells in the human cervix and implications for HIV transmission. Am J Reprod Immunol $2014 ; 71: 252-64$.

4. Shen R, Richter HE, Clements RH, et al. Macrophages in vaginal but not intestinal mucosa are monocyte-like and permissive to human immunodeficiency virus type 1 infection. J Virol 2009; 83 :3258-67.

5. Swaims-Kohlmeier A, Haaland RE, Haddad LB, et al. Progesterone levels associate with a novel population of CCR5+ CD38+ CD4 T cells resident in the genital mucosa with lymphoid trafficking potential. J Iтmиnol 2016; 197 : 368-76.

6. Duluc D, Gannevat J, Anguiano E, et al. Functional diversity of human vaginal APC subsets in directing T-cell responses. Mucosal Immunol $2013 ; 6: 626-38$.

7. Rodriguez-Garcia M, Shen Z, Barr FD, et al. Dendritic cells from the human female reproductive tract rapidly capture and respond to HIV. Mucosal Immunol 2017; $10: 531-44$.

8. Shen R, Kappes JC, Smythies LE, Richter HE, Novak L, Smith PD. Vaginal myeloid dendritic cells transmit founder HIV-1. $J$ Virol $2014 ; 88: 7683-8$.

9. Rodriguez-Garcia M, Barr FD, Crist SG, Fahey JV, Wira CR. Phenotype and susceptibility to HIV infection of CD4+ Th17 cells in the human female reproductive tract. Mucosal Immunol $2014 ; 7$ : 1375-85.

10. Stary G, Olive A, Radovic-Moreno AF, et al. VACCINES. A mucosal vaccine against Chlamydia trachomatis generates two waves of protective memory T cells. Science $2015 ; 348$ : aaa8205.

11. Pudney J, Quayle AJ, Anderson DJ. Immunological microenvironments in the human vagina and cervix: mediators of cellular immunity are concentrated in the cervical transformation zone. Biol Reprod $2005 ; 73: 1253-63$.

12. Ganor Y, Zhou Z, Tudor D, et al. Within $1 \mathrm{~h}, \mathrm{HIV}-1$ uses viral synapses to enter efficiently the inner, but not outer, foreskin mucosa and engages Langerhans-T cell conjugates. Mucosal Immunol 2010; 3 :506-22.

13. Anderson D, Politch JA, Pudney J. HIV infection and immune defense of the penis. Am J Reprod Immunol $2011 ; 65: 220-9$.

14. Pudney J, Anderson D. Innate and acquired immunity in the human penile urethra. J Reprod Immunol 2011 ; $88: 219-27$.

15. Ganor $Y$, Zhou Z, Bodo $J$, et al. The adult penile urethra is a novel entry site for HIV-1 that preferentially targets resident urethral macrophages. Mucosal Immunol 2013; 6:776-86.

16. Abreu MT. Toll-like receptor signalling in the intestinal epithelium: how bacterial recognition shapes intestinal function. Nat Rev Immunol $2010 ; 10: 131-44$.

17. Preza GC, Tanner K, Elliott J, Yang OO, Anton PA, Ochoa MT. Antigen-presenting cell candidates for HIV-1 transmission in human distal colonic mucosa defined by CD207 dendritic cells and CD209 macrophages. AIDS Res Hum Retroviruses 2014 ; 30 : 241-9.

18. Isidro RA, Appleyard CB. Colonic macrophage polarization in homeostasis, inflammation and cancer. Am J Physiol Gastrointest Liver Physiol 2016;311: G59-73.

19. Anderson DJ, Politch JA, Nadolski AM, Blaskewicz CD, Pudney J, Mayer KH. Targeting Trojan horse leukocytes for HIV prevention. AIDS 2010; $24: 163-87$.

20. Shen R, Richter HE, Smith PD. Interactions between HIV-1 and mucosal cells in the female reproductive tract. Am J Reprod Immunol 2014; $71: 608-17$.

21. Burgener A, McGowan I, Klatt NR. HIV and mucosal barrier interactions: consequences for transmission and pathogenesis. Curr Opin Immunol $2015 ; 36: 22-30$.

22. Doncel GF, Anderson S, Zalenskaya I. Role of semen in modulating the female genital tract microenvironment-implications for HIV transmission. Am J Reprod Immunol 2014 ; 71 : 564-74.
23. Doncel GF, Joseph T, Thurman AR. Role of semen in HIV-1 transmission: inhibitor or facilitator? Am J Reprod Immunol 2010 ; 65 : 292-301.

24. Lawrence $\mathrm{P}$, Portran D, Terrasse R, et al. Selective transmigration of monocyte-associated HIV-1 across a human cervical monolayer and its modulation by seminal plasma. AIDS 2012;26:785-96.

25. Mullin JM, Diguilio KM, Valenzano MC, et al. Zinc reduces epithelial barrier compromise induced by human seminal plasma. PLoS One $2017 ; 12$ : e0170306.

26. Bouhlal H, Chomont N, Haeffner-Cavaillon N, Kazatchkine MD, Belec L, Hocini H. Opsonization of HIV-1 by semen complement enhances infection of human epithelial cells. J Immunol 2002 ; 169:3301-6.

27. Crisci E, Ellegard R, Nystrom S, et al. Complement opsonization promotes herpes simplex virus 2 infection of human dendritic cells. $J$ Virol 2016; $90: 4939-50$.

28. Tjomsland V, Ellegard R, Kjolhede P, et al. Blocking of integrins inhibits HIV-1 infection of human cervical mucosa immune cells with free and complement-opsonized virions. Eur J Immunol $2013 ; 43$ : 2361-72.

29. Munch J, Rucker E, Standker L, et al. Semen-derived amyloid fibrils drastically enhance HIV infection. Cell 2007; $131: 1059-71$.

30. Roan NR, Liu H, Usmani SM, et al. Liquefaction of semen generates and later degrades a conserved semenogelin peptide that enhances HIV infection. $J$ Virol $2014 ; 88: 7221-34$.

31. Camus C, Matusali G, Bourry O, et al. Comparison of the effect of semen from HIV-infected and uninfected men on CD4+ T-cell infection. AIDS 2016; 30 : 1197-208.

32. Sabatte J, Faigle W, Ceballos A, et al. Semen clusterin is a novel DC-SIGN ligand. J Immunol 2011; 187 : 5299-309.

33. Stax MJ, van Montfort $T$, Sprenger RR, et al. Mucin 6 in seminal plasma binds DC-SIGN and potently blocks dendritic cell mediated transfer of HIV-1 to CD4(+) T-lymphocytes. Virology 2009; 391 : 203-11.

34. Drannik AG, Nag K, Sallenave JM, Rosenthal KL. Antiviral activity of trappin-2 and elafin in vitro and in vivo against genital herpes. J Virol 2013; $87: 7526-38$.

35. Kaushic C, Nazli A, Ferreira VH, Kafka JK. Primary human epithelial cell culture system for studying interactions between female upper genital tract and sexually transmitted viruses, HSV-2 and HIV-1. Methods $2011 ; 55: 114-21$.

36. Bomsel M, Alfsen A. Entry of viruses through the epithelial barrier: pathogenic trickery. Nat Rev Mol Cell Biol 2003; 4 :57-68.

37. Cavarelli M, Foglieni C, Rescigno M, Scarlatti G. R5 HIV-1 envelope attracts dendritic cells to cross the human intestinal epithelium and sample luminal virions via engagement of the CCR5. EMBO Mol Med $2013 ; 5: 776-94$.

38. Andrei G. Three-dimensional culture models for human viral diseases and antiviral drug development. Antiviral Res 2006; 71 :96-107.

39. Bouschbacher M, Bomsel M, Verronese E, et al. Early events in HIV transmission through a human reconstructed vaginal mucosa. AIDS $2008 ; 22: 1257-66$.

40. Sivard P, Berlier W, Picard B, Sabido O, Genin C, Misery L. HIV-1 infection of Langerhans cells in a reconstructed vaginal mucosa. $J$ Infect Dis 2004; $190: 227-35$.

41. Kolodkin-Gal D, Hulot SL, Korioth-Schmitz B, et al. Efficiency of cell-free and cell-associated virus in mucosal transmission of human immunodeficiency virus type 1 and simian immunodeficiency virus. $J$ Virol 2013;87: 13589-97.

42. Maher D, Wu X, Schacker T, Horbul J, Southern P. HIV binding, penetration, and primary infection in human cervicovaginal tissue. Proc Natl Acad Sci U S A 2005 ; 102 : 11504-9.

43. Collins KB, Patterson BK, Naus GJ, Landers DV, Gupta P. Development of an in vitro organ culture model to study transmission of HIV-1 in the female genital tract. Nat Med 2000; 6:475-9.

44. Tugizov SM, Herrera R, Veluppillai $\mathrm{P}$, et al. Differential transmission of HIV traversing fetal oral/intestinal epithelia and adult oral epithelia. $J$ Virol $2011 ; 86: 2556-70$. 
45. Tsilingiri K, Rescigno M. Should probiotics be tested on ex vivo organ culture models? Gut Microbes $2012 ; 3: 442-8$.

46. Shen R, Drelichman ER, Bimczok D, et al. GP41-specific antibody blocks cell-free HIV type 1 transcytosis through human rectal mucosa and model colonic epithelium. J Immunol 2010; 184:3648-55.

47. Fletcher PS, Elliott J, Grivel JC, et al. Ex vivo culture of human colorectal tissue for the evaluation of candidate microbicides. AIDS $2006 ; 20: 1237-45$.

48. Dezzutti CS, Russo J, Wang L, et al. Development of HIV-1 rectal-specific microbicides and colonic tissue evaluation. PLoS One 2014; 9: e102585.

49. Houzet L, Matusali G, Dejucq-Rainsford N. Origins of HIV-infected leukocytes and virions in semen. J Infect Dis 2014 ; 210 : S622-30.

50. Roulet V, Satie AP, Ruffault A, et al. Susceptibility of human testis to human immunodeficiency virus-1 infection in situ and in vitro. Am J Pathol $2006 ; 169: 2094-103$.

51. Le Tortorec A, Satie AP, Denis H, et al. Human prostate supports more efficient replication of HIV-1 R5 than X4 strains ex vivo. Retrovirology $2008 ; 5: 119$.

52. Deleage C, Moreau M, Rioux-Leclercq N, Ruffault A, Jegou B, Dejucq-Rainsford N. Human immunodeficiency virus infects human seminal vesicles in vitro and in vivo. Am J Pathol 2011; 179:2397-408.

53. Matusali G, Dereuddre-Bosquet N, Le Tortorec A, et al. Detection of Simian immunodeficiency virus in semen, urethra, and male reproductive organs during efficient highly active antiretroviral therapy. $J$ Virol $2015 ; 89: 5772-87$.

54. MacDonald EM, Savoy A, Gillgrass A, et al. Susceptibility of human female primary genital epithelial cells to herpes simplex virus, type- 2 and the effect of TLR3 ligand and sex hormones on infection. Biol Reprod $2007 ; 77: 1049-59$.

55. Nazli A, Yao XD, Smieja M, Rosenthal KL, Ashkar AA, Kaushic C. Differential induction of innate anti-viral responses by TLR ligands against Herpes simplex virus, type 2 , infection in primary genital epithelium of women. Antiviral Res 2009; $81: 103-12$.

56. Howell AL, Edkins RD, Rier SE, et al. Human immunodeficiency virus type 1 infection of cells and tissues from the upper and lower human female reproductive tract. J Virol 1997 ; 71 : 3498-506.

57. Greenhead P, Hayes $P$, Watts PS, Laing KG, Griffin GE, Shattock RJ. Parameters of human immunodeficiency virus infection of human cervical tissue and inhibition by vaginal virucides. $J$ Virol $2000 ; 74: 5577-86$.

58. Micsenyi AM, Zony C, Alvarez RA, Durham ND, Chen BK, Klotman ME. Postintegration HIV-1 infection of cervical epithelial cells mediates contact-dependent productive infection of T cells. $J$ Infect Dis $2013 ; 208$ : 1756-67.

59. Dezzutti CS, Guenthner PC, Cummins Jr. JE, et al. Cervical and prostate primary epithelial cells are not productively infected but sequester human immunodeficiency virus type 1 . J Infect Dis $2001 ; 183: 1204-13$.

60. Wu Z, Chen Z, Phillips DM. Human genital epithelial cells capture cell-free human immunodeficiency virus type 1 and transmit the virus to CD4+ Cells: implications for mechanisms of sexual transmission. J Infect Dis 2003; $188: 1473-82$.

61. Salle B, Brochard $\mathrm{P}$, Bourry $\mathrm{O}$, et al. Infection of macaques after vaginal exposure to cell-associated simian immunodeficiency virus. $J$ Infect Dis $2010 ; 202: 337-44$.

62. Ribeiro Dos Santos P, Rancez M, Pretet JL, et al. Rapid dissemination of SIV follows multisite entry after rectal inoculation. PLoS One $2011 ; 6: \mathrm{e} 19493$.

63. Miller CJ, Hu J. T cell-tropic simian immunodeficiency virus (SIV) and simian-human immunodeficiency viruses are readily transmitted by vaginal inoculation of rhesus macaques and Langerhans' cells of the female genital tract are infected with SIV. J Infect Dis 1999; 179: S413-7.

64. Hu J, Gardner MB, Miller CJ. Simian immunodeficiency virus rapidly penetrates the cervicovaginal mucosa after intravaginal inoculation and infects intraepithelial dendritic cells. J Virol 2000; 74 : 6087-95.
65. Visalli RJ, Courtney RJ, Meyers C. Infection and replication of herpes simplex virus type 1 in an organotypic epithelial culture system. Virology $1997 ; 230: 236-43$.

66. Meyers C, Andreansky SS, Courtney RJ. Replication and interaction of herpes simplex virus and human papillomavirus in differentiating host epithelial tissue. Virology $2003 ; 315: 43-55$.

67. Bodily JM, Alam S, Chen H, Meyers C. Organotypic raft cultures and the study of the natural history of papillomavirus. In : Campo MS, ed. Papillomavirus research: from natural history to vaccines and beyond. Caister Academic Press, 2006, p. 145-73.

68. Dollard SC, Wilson JL, Demeter LM, et al. Production of human papillomavirus and modulation of the infectious program in epithelial raft cultures. Genes Dev 1992; 6 : 1131-42.

69. Meyers C, Frattini MG, Hudson JB, Laimins LA. Biosynthesis of human papillomavirus from a continuous cell line upon epithelial differentiation. Science 1992; 257 : 971-3.

70. Horbul JE, Schmechel SC, Miller BR, Rice SA, Southern PJ. Herpes simplex virus-induced epithelial damage and susceptibility to human immunodeficiency virus type 1 infection in human cervical organ culture. PLoS One 2011; 6: e22638.

71. Nazli A, Chan O, Dobson-Belaire WN, et al. Exposure to HIV-1 directly impairs mucosal epithelial barrier integrity allowing microbial translocation. PLoS Pathog 2010; 6 : e1000852.

72. Nazli A, Kafka JK, Ferreira VH, et al. HIV-1 gp120 induces TLR2and TLR4-mediated innate immune activation in human female genital epithelium. J Immunol 2013; 191 : 4246-58.

73. Zhou Z, Xu L, Sennepin A, et al. The HIV-1 viral synapse signals human foreskin keratinocytes to secrete thymic stromal lymphopoietin facilitating HIV-1 foreskin entry. Mucosal Immunol 2017; 11 : 158-71.

74. Hladik F, Sakchalathorn $P$, Ballweber $L$, et al. Initial events in establishing vaginal entry and infection by human immunodeficiency virus type-1. Immunity $2007 ; 26: 257-70$.

75. Ballweber L, Robinson B, Kreger A, et al. Vaginal Langerhans cells nonproductively transporting HIV-1 mediate infection of T cells. J Virol $2011 ; 85: 13443-7$.

76. Bomsel M. Transcytosis of infectious human immunodeficiency virus across a tight human epithelial cell line barrier. Nat Med 1997 ; 3 : $42-7$.

77. Bomsel M, Pastori C, Tudor D, et al. Natural mucosal antibodies reactive with first extracellular loop of CCR5 inhibit HIV-1 transport across human epithelial cells. AIDS $2007 ; 21: 13-22$.

78. Bomsel M, Heyman M, Hocini $\mathrm{H}$, et al. Intracellular neutralization of HIV transcytosis across tight epithelial barriers by anti-HIV envelope protein dIgA or IgM. Immunity 1998; 9: 277-87.

79. Martin-Latil S, Gnadig NF, Mallet A, et al. Transcytosis of HTLV1 across a tight human epithelial barrier and infection of subepithelial dendritic cells. Blood 2012;120:572-80.

80. Hocini $\mathrm{H}$, Becquart $\mathrm{P}$, Bouhlal $\mathrm{H}$, et al. Active and selective transcytosis of cell-free human immunodeficiency virus through a tight polarized monolayer of human endometrial cells. J Virol $2001 ; 75: 5370-4$.

81. Bobardt MD, Chatterji U, Selvarajah S, et al. Cell-free human immunodeficiency virus type 1 transcytosis through primary genital epithelial cells. J Virol $2007 ; 81: 395-405$.

82. Alfsen A, Yu H, Magerus-Chatinet A, Schmitt A, Bomsel M. HIV-1infected blood mononuclear cells form an integrin- and agrin-dependent viral synapse to induce efficient HIV-1 transcytosis across epithelial cell monolayer. Mol Biol Cell $2005 ; 16$ : 4267-79.

83. Stoddard E, Ni H, Cannon G, et al. gp340 promotes transcytosis of human immunodeficiency virus type 1 in genital tract-derived cell lines and primary endocervical tissue. J Virol 2009; $83: 8596-603$.

84. Carreno MP, Chomont N, Kazatchkine MD, et al. Binding of LFA1 (CD11a) to intercellular adhesion molecule 3 (ICAM-3; CD50) and ICAM-2 (CD102) triggers transmigration of human immunodeficiency virus type 1-infected monocytes through mucosal epithelial cells. J Virol $2002 ; 76: 32-40$. 
85. Chancey CJ, Khanna KV, Seegers JF, et al. Lactobacilli-expressed single-chain variable fragment ( $\mathrm{scFv}$ ) specific for intercellular adhesion molecule 1 (ICAM-1) blocks cell-associated HIV-1 transmission across a cervical epithelial monolayer. J Immunol 2006; 176:5627-36.

86. Pearce Pratt R, Phillips DM. Studies of adhesion of lymphocytic cells: implications for sexual transmission of human immunodeficiency virus. Biol Reprod 1993; 48:431-45.

87. Fox-Canale AM, Hope TJ, Martinson J, et al. Human cytomegalovirus and human immunodeficiency virus type-1 co-infection in human cervical tissue. Virology 2007 ; 369: 55-68.

88. Patterson BK, Landay A, Siegel JN, et al. Susceptibility to human immunodeficiency virus-1 infection of human foreskin and cervical tissue grown in explant culture. Am J Pathol 2002; 161 : 867-73.

89. Fischetti L, Barry SM, Hope TJ, Shattock RJ. HIV-1 infection of human penile explant tissue and protection by candidate microbicides. AIDS 2009; $23: 319-28$

90. Gupta P, Collins KB, Ratner D, et al. Memory CD4(+) T cells are the earliest detectable human immunodeficiency virus type 1 (HIV-1)-infected cells in the female genital mucosal tissue during HIV-1 transmission in an organ culture system. J Virol 2002; 76:9868-76.

91. Rollenhagen C, Asin SN. Enhanced HIV-1 replication in ex vivo ectocervical tissues from post-menopausal women correlates with increased inflammatory responses. Mucosal Immunol $2011 ; 4: 671-81$.

92. Saba E, Origoni M, Taccagni G, et al. Productive HIV-1 infection of human cervical tissue ex vivo is associated with the secretory phase of the menstrual cycle. Mucosal Immunol 2013; 6 : 1081-90.

93. Saba E, Grivel JC, Vanpouille C, et al. HIV-1 sexual transmission: early events of HIV-1 infection of human cervico-vaginal tissue in an optimized ex vivo model. Mucosal Immunol 2010; $3: 280-90$.

94. Andrei G, van den Oord J, Fiten $\mathrm{P}$, et al. Organotypic epithelial raft cultures as a model for evaluating compounds against alphaherpesviruses. Antimicrob Agents Chemother 2005 ; 49:4671-80.
95. Dezzutti CS. Animal and human mucosal tissue models to study HIV biomedical interventions: can we predict success? J Int AIDS Soc $2015 ; 18: 20301$.

96. Herrera C, Cranage M, McGowan I, Anton P, Shattock RJ. Reverse transcriptase inhibitors as potential colorectal microbicides. Antimicrob Agents Chemother 2009; 53 : 1797-807.

97. Fletcher P, Harman S, Azijn H, et al. Inhibition of human immunodeficiency virus type 1 infection by the candidate microbicide dapivirine, a non-nucleoside reverse transcriptase inhibitor. Antimicrob Agents Chemother $2009 ; 53: 487-95$.

98. Herrera C, Cranage M, McGowan I, Anton P, Shattock RJ. Colorectal microbicide design: triple combinations of reverse transcriptase inhibitors are optimal against HIV-1 in tissue explants. AIDS 2011;25: 1971-9.

99. Cole AL, Herasimtschuk A, Gupta P, Waring AJ, Lehrer RI, Cole $\mathrm{AM}$. The retrocyclin analogue $\mathrm{RC}-101$ prevents human immunodeficiency virus type 1 infection of a model human cervicovaginal tissue construct. Immunology $2007 ; 121: 140-5$.

100. Abner SR, Guenthner PC, Guarner J, et al. A human colorectal explant culture to evaluate topical microbicides for the prevention of HIV infection. J Infect Dis 2005; 192: 1545-56.

101. Cummins Jr. JE, Guarner J, Flowers L, et al. Preclinical testing of candidate topical microbicides for anti-human immunodeficiency virus type 1 activity and tissue toxicity in a human cervical explant culture. Antimicrob Agents Chemother $2007 ; 51: 1770-9$.

102. Pyles RB, Vincent KL, Baum MM, et al. Cultivated vaginal microbiomes alter HIV-1 infection and antiretroviral efficacy in colonized epithelial multilayer cultures. PLoS One 2014;9: e93419.

103. Fricain JC, De Olivera H, Devillard R, et al. 3D bioprinting in regenerative medicine and tissue engineering. Med Sci (Paris) 2017;33: $52-9$. 